\title{
Demonstration of a Free-Piston Rapid Compression Facility for the Study of High Temperature Combustion Phenomena
}

\author{
M. T. Donovan, X. He, B. T. Zigler, T. R. Palmer, M. S. Wooldridge, and A. Atreya \\ Department of Mechanical Engineering \\ University of Michigan \\ 2350 Hayward St. \\ Ann Arbor, MI, USA 48109-2125
}

\begin{abstract}
A free-piston rapid-compression facility (RCF) has been developed at the University of Michigan (UM) for use in studying high-temperature combustion phenomena, including gasphase combustion synthesis and homogeneous charge compression ignition systems. The facility is designed to rapidly compress a mixture of test gases in a nearly adiabatic process. A range of compression ratios, currently 16 to 37 , can be obtained. The high temperatures and pressures generated by the RCF can be maintained for in excess of $50 \mathrm{~ms}$, providing an order of magnitude increase in observation time over what can be obtained using shock tubes. The facility is instrumented for temperature and pressure measurements as well as optical access for use with laser and other optical diagnostics. This work describes the UM-RCF and its operation, establishes obtainable pressures and temperatures (over $1900 \mathrm{kPa}$ and $970 \mathrm{~K}$ for predominately $\mathrm{N}_{2}$ gas mixtures, and over $785 \mathrm{kPa}$ and $2000 \mathrm{~K}$ for $\mathrm{Ar}$ gas mixtures), and demonstrates the repeatability of the UM-RCF experiments $(<3 \%$ run-to-run variability in peak pressure) for combustion studies. The experimental results for time histories of temperature and pressure are interpreted using analytical isentropic models. Comparison between the isentropic predictions and the experimental data indicate excellent agreement and support the conclusion that the core region of the test gases is nominally uniform and is compressed isentropically.
\end{abstract}




\section{Introduction}

The study of complex combustion chemistry requires experimental facilities that can replicate combustion environments of interest. Chemical kinetics can have considerable impact on characteristics important in many combustion systems. For example, ignition delay and particle nucleation can have long characteristic times [1] that are dominated by reaction kinetics [2]. In both these systems, the study of the chemical kinetics is fundamental to the overall understanding of the respective combustion processes.

Ignition studies are of considerable importance in the development of advanced internal combustion engine strategies. Of particular interest are homogenous charge compression ignition (HCCI) systems as these engines are compression ignited, lean burn, and have no throttling losses, which leads to high efficiency and low $\mathrm{NO}_{\mathrm{x}}$ emissions [3]. In HCCI engines, combustion is achieved through control of the temperature, pressure, and composition of the reactant mixture, and extensive understanding of the chemical kinetics of ignition is required to develop control strategies.

The process of particle nucleation (the formation of particles $<5-10 \mathrm{~nm}$ in size) is the least understood step in particle formation and growth in combustion systems [4]. The ability to control the creation and growth of particles is critical to minimize, or ideally eliminate, particulate pollution. Additionally, increased understanding of particle nucleation can be used to design and create nano-particles at the molecular level.

Desirable characteristics for an experimental combustion chemistry facility to study relatively long time combustion phenomena include high temperatures (and pressures), simple flow fields, good measurement access, and sufficient test times to examine the phenomena of interest. Existing experimental tools have some of these characteristics. Shock tubes generate 
high temperatures without complicated flow dynamics and are ideal for the study of combustion phenomena with fast characteristic times. However, the uniform elevated temperature and pressure post-shock conditions typically persist for less than $5 \mathrm{~ms}$ [5]. On the other hand, a rapid compression facility (RCF) is capable of generating high temperatures and pressures, with simplified fluid mechanics, for sustained periods (greater than $10 \mathrm{~ms}$ ).

In its most basic form, the RCF can be described as a simple piston-cylinder device. An external force (usually a compressed gas or a pressurized liquid) is used to rapidly accelerate the piston within the cylinder. The piston compresses the test gas mixture in the cylinder, much like the compression stroke of an internal combustion (IC) engine, leading to a very rapid increase in pressure and temperature. By preventing piston rebound, the high pressure and temperature conditions can be sustained for a relatively long duration $(>10 \mathrm{~ms})$. Due to the speed of the compression process, there is little time for heat transfer and the bulk of the test gas mixture is thermally isolated from the RCF (i.e. cooling due to heat transfer is restricted to a thin layer of gases along the bounding surfaces of the RCF). The effect of limited heat transfer is that conditions (temperature, pressure, and species concentration) within a core region of the compression mixture are (nominally) spatially uniform.

Various researchers have used rapid-compression facilities for generating high pressure and temperature conditions. Investigations using RCFs have focused primarily on ignition delay, auto-ignition and two-stage ignition phenomena.

Griffiths and co-workers at Leeds University have used a pneumatically driven piston for autoignition studies [6,7] of hydrocarbon fuels and the investigation of single and two-stage ignition of alkanes [8]. In support of their experimental work, this group studied the development of the temperature field [9], performed computational fluid dynamics (CFD) 
modeling [10], and performed extensive kinetics modeling of reaction chemistry [11, 2]. Recently, the Leeds research group has studied the thermokinetic interactions that lead to knock in HCCI using image intensified, natural light output to characterize the reaction [12]. The Leeds RCF achieves compression ratios up to 14.6. Compression occurs in $22 \mathrm{~ms}$, and final temperatures of 530 to $1000 \mathrm{~K}$ and pressures up to $2000 \mathrm{kPa}$ are realized.

Minetti and co-workers, at the University of Science and Technology (UST) at Lille, used an RCF to study auto-ignition [13] and two-stage ignition [14, 15, 16] of hydrocarbon fuels. In support of their experimental work, this group investigated the temperature distribution within their RCF [17, 18] and conducted kinetic modeling of their RCF experiments [13, 19]. The UST RCF system uses a dual piston design: an air-driven drive piston is connected, by way of a cam, to a second piston that compresses the test gas mixture. The design of the cam controls the stroke of the compressing piston and prevents rebound of the compressing piston when it reaches full extension. The UST RCF is capable of achieving a compression ratio of approximately 10. Final pressures of up to $1700 \mathrm{kPa}$ and temperatures of $900 \mathrm{~K}$ have been reported with compression times of 20 to $60 \mathrm{~ms}$ using this facility.

Lee and Hochgreb at the Massachusetts Institute of Technology (MIT) used an air driven, oil damped RCF piston system [20] to study hydrogen auto-ignition [21]. Lee and Hochgreb have performed detailed modeling of the suppression of vortices, which are formed by the piston in this facility during compression, and the heat transfer that occurs within the MIT RCF [22]. This modeling work led to modifications to their piston design to capture the vortices created during the compression process and hence reduce fluid motion, and the subsequent heat transfer, in the test gas. More recently, Tanaka and co-workers have used this RCF to study the effects of fuel structure and additives on HCCI combustion [23, 24]. The maximum pressure, compression 
ratio, and temperature achieved using the MIT device were $7 \mathrm{MPa}, 19$, and $1200 \mathrm{~K}$, respectively. Compression in 10 to $30 \mathrm{~ms}$ was reported.

Researchers at the National University of Ireland (NUI), Galway used an RCF to study methane and propane ignition $[25,26]$. The NUI RCF is a novel design that incorporates opposed pistons to rapidly compress a test gas mixture [27]. Compression ratios as high as 13.4 have been reported using this RCF and peak compression pressures and temperatures of $4 \mathrm{MPa}$ and $1060 \mathrm{~K}$, respectively, have been reported. The compression time using this RCF is less than $20 \mathrm{~ms}$.

As demonstrated by the results of other researchers using RCFs, the sustained high temperature and pressure environment created by an RCF provide an excellent research tool for simulating adiabatic compression and ignition. These conditions also happen to be well suited to the study of particle nucleation phenomena. The extended duration high temperature environment permits the monitoring of chemical reactions as they evolve over time. The simplified fluid mechanics found in RCFs permit rather straightforward determination of the combustion conditions. The good measurement access afforded by RCFs also allows for the use of a wide range of optical and physical diagnostics.

A free-piston rapid-compression machine, originally designed by TRW to study sooting in hydrocarbon flames [28], has been relocated to the Department of Mechanical Engineering at the University of Michigan (UM). The RCF has been installed and refurbished for use in studying high-temperature combustion phenomena. Prior to using the UM-RCF for combustion studies, the performance of the device must be characterized with benchmarking experiments. To properly characterize performance, it is necessary to demonstrate the UM-RCF generates test conditions conducive to the study of a range of combustion phenomena. Furthermore, these test 
conditions should be both repeatable and predictable. The current work describes the UM-RCF and its operation, and presents the results of characterization studies of the UM-RCF, including analytical models developed to predict the performance of the RCF over a range of operating conditions. The results of the benchmark experiments will confirm the ability of the RCF to repeatably achieve sustained high-temperature and high-pressure operating conditions.

\section{Experimental Facility}

\section{Hardware and Instrumentation}

A schematic and photograph of the UM-RCF are shown in Fig. 1. The key components of the UM-RCF are the driver section, the driven section, the test manifold, the sabot (free-piston), and the hydraulic control valve assembly. The UM-RCF uses pressurized gas to accelerate the sabot down the bore of the driven section. The test gases are loaded into the driven section, in front of the sabot, and are compressed as the sabot traverses the length of the driven section. The sabot lodges in the test manifold, confining a portion of the compressed gases within the test manifold of the UM-RCF.

The driver section is a $5.54 \mathrm{~m}$ long carbon steel pipe with a $154 \mathrm{~mm}$ inner diameter. The section is capped on one end and separated from the driven section on the other end by a 101.6 mm diameter globe valve. The driver section acts as a reservoir for the pressured gas (typically air) used to propel the sabot during a UM-RCF experiment.

The driven section is a $2.74 \mathrm{~m}$ long stainless steel tube. The inner surface is chromed and honed to a diameter of $101.2 \mathrm{~mm}$. The driven section is connected to the globe valve at one end and the test manifold at the other end. Test gases mixtures are loaded into the driven section prior to operating the UM-RCF and the driven section acts as the cylinder through which the sabot travels during operation of the UM-RCF. 
The test manifold consists of four components: the convergent section, the extension section, the thermocouple manifold, and the instrumented test section. The stainless steel convergent section is $101.6 \mathrm{~mm}$ long and bridges the $101.2 \mathrm{~mm}$ bore of the driven section with the $50.8 \mathrm{~mm}$ bore of the remainder of the test manifold components. The extension section is a stainless steel tube $(50.8 \mathrm{~mm}$ bore $)$ that provides the contact surface used to halt the motion of the sabot. Two sections are available for use $(81 \mathrm{~mm}$ or $126 \mathrm{~mm}$ in length), which allow for control of the overall compression ratio of the UM-RCF. The polycarbonate thermocouple manifold is designed for the mounting of fine wire thermocouples across the bore of the test manifold (see Fig. 2). Like the other components in the test manifold, the thermocouple manifold has a bore of $50.8 \mathrm{~mm}$. The length of the thermocouple manifold varies by design and is either 16.2 or $25.4 \mathrm{~mm}$ long, which alloys for further control of the overall compression ratio of the UM-RCF. This component is optional and can be removed for experiments where temperature measurements are either unnecessary or conditions are unsuitable for the use of fine wire thermocouples.

The instrumented test section, depicted in Fig. 3, contains two optical ports (for use with optical diagnostics), a pressure transducer port, an additional instrumentation port and a gas inlet/outlet port. The test section has a length of $50.8 \mathrm{~mm}$. An end wall seals the test manifold. Typically, the end wall is a $6.3 \mathrm{~mm}$ thick steel plate, although it can be replaced with at $12.7 \mathrm{~mm}$ thick polycarbonate plate that permits additional optical access to the test manifold. A third option involves replacing the end wall with a fast acting valve connected to an evacuated expansion tank. The valve and expansion tank can be used to rapidly quench the gases in the test volume, permitting the "freezing" of test conditions at a pre-selected time after the completion of compression. 
The sabot is constructed of two parts (Fig. 4), an acetal resin (Delrin ${ }^{\mathrm{TM}}$ ) body and an ultra-high molecular weight (UHMW) polyethylene replaceable nose cone. Two spring-loaded U-rings seal the sabot in the bore of the test section and prevent blow-by of the pressurized driver gases used to accelerate the sabot. The nose cone is slightly tapered such that it will seal in the extension section of the test manifold with an interference fit.

A key advantage of the sabot design is that not all the gas in the driven section is compressed into the test section. A stirring vortex is created by the relative motion between the piston and the cylinder wall. Depending on the design of the sabot and the driven section, this vortex can travel into the extension section and increase gas motion in the test section, which is undesirable. Increased gas motion leads to large uncertainties in temperature, due to cooling, and therefore large variations in species concentrations and other parameters of interest. The sabot design used in this study seals the nose cone into the extension section before the boundary vortex travels into the extension section, reducing gas motion, and therefore cooling, in the test section.

The hydraulic control valve assembly consists of a fast-acting globe valve (Fisher V-500) that is actuated by a custom designed manifold (Shore Western D24330-1) attached to a servo valve (Moog Model 760-103). Pressurized hydraulic oil is used as the operating fluid in the hydraulic pump/valve manifold system. Control of the servo valve is provided by a programmable servo controller (Shore Western 5C3000C). The valve is capable of cycling (fully closed to fully open to fully closed) in approximately $50 \mathrm{~ms}$. Typical experimental cycle times are on the order of 60 to $120 \mathrm{~ms}$.

A gas manifold provides for the regulation of all gas flows to and from the driven section and the test manifold. The gas manifold is used to evacuate and charge the UM-RCF, monitor 
pressures within the UM-RCF during charging and evacuation and to prepare test gas mixtures. Test gas mixtures are typically prepared in a mixing tank. The test gas mixture composition is determined by measurement of the partial pressures of the various gas components using three capacitance manometers (Varian models VCMT11T, VCMT12T, and VCMT13T) with $1.3 \mathrm{kPa}$, $13.3 \mathrm{kPa}$, and $133 \mathrm{kPa}$ maximum scales, and a Bourdon tube gauge (Omega DPG5000-L) with a maximum scale of $410 \mathrm{kPa}$.

The following diagnostics are installed in the test manifold of the UM-RCF. A piezoelectric transducer (Kistler 6041AX4 with Type 5010B charge amplifier) is used to record dynamic pressures during the test period $(<10 \mu$ s time response and dynamic range of 0 to $5000 \mathrm{kPa})$. A thermal isolation coating (RTV) on the pressure transducer was used in some experiments to test the influence of thermal shock. (The results indicated that thermal shock had no effect on the performance of the transducer.) Temperatures during the test period are recorded using uncoated $0.025 \mathrm{~mm}$ diameter $(\sim 0.080 \mathrm{~mm}$ bead diameter) S-type (Pt/Pt-10\% Rh) thermocouples (Omega Engineering, P10R-001). Typically, two thermocouples are installed in the temperature measurement section. One thermocouple bead is located nominally in the center of the chamber (25.4 $\mathrm{mm}$ from the wall) and the second thermocouple bead is located near the wall of the thermocouple manifold (within $2 \mathrm{~mm}$, see Fig. 2). Typical performance characteristics of the thermocouples are discussed below. The sabot position measurement system consists of a pair of diode lasers (TIM-201-3, $3 \mathrm{~mW}, 650 \mathrm{~nm}$ ) and unamplified silicon photo-detectors (Hamamatsu S1787-12, $3 \mathrm{~dB}$ response time $<10 \mathrm{~ms}$ ) that record the location of the sabot near the end of its travel (see Fig. 1). Passage of the sabot interrupts the laser beams, recording the location of the sabot within the driven section. The sabot position within the driven section is used to develop volume time-histories of the test gas for use in computational 
modeling of the compression process. Optical ports in the test section provide access for both absorption and emission spectroscopy. Data are recorded using a high-resolution digital data acquisition system (National Instruments PXI NI4472 data acquisition board) with a sampling rate of $100 \mathrm{kHz}$ and 24-bit resolution. Simultaneous data acquisition is provided by a high-speed four channel digital oscilloscope (HP Infinium 54845).

\section{Operation}

Operation of the UM-RCF begins with loading the sabot into the driven section just downstream of the globe valve (which is in the closed position). All connections are secured and the device is leak tested. Typical leak rates of the combined driven section and test manifold are $<2 \mathrm{~Pa}$ (0.015 torr) per minute. The driven section is evacuated to below $400 \mathrm{~Pa}$ ( 3 torr) and purged with an inert gas $\left(\mathrm{N}_{2}\right.$ or Ar). After three purges, the driven section is evacuated to below $35 \mathrm{~Pa}$ ( 0.25 torr) and charged with the test gas mixture. Typically test gas mixtures are prepared in advance and stored in a dedicated mixing tank. Initial test gas pressures range from 2.5 to $30 \mathrm{kPa}$ (20 to 220 torr). All test gases used in this study have a purity of at least $99.998 \%$ (except $\mathrm{O}_{2}$ which has a purity of at least $99.98 \%$ ).

Once the test mixture has been loaded into the driven section, all isolation valves are closed, the data acquisition equipment is readied, and the driver section is pressurized with air (103 to $290 \mathrm{kPa}$ ). The globe valve is then rapidly cycled using the servo controller. The pressurized gas from the driver section accelerates the sabot down the length of the driven section, rapidly compressing the test gas mixture into the test manifold. The compression process is depicted in Fig. 5 as a series of four drawings that show the sabot as it compresses the test gas mixture within the UM-RCF. The sabot motions stops when the nose cone of the sabot lodges in the extension section. (The sabot body typically separates from the nose cone at this 
point, rebounds, and comes to rest within the driven section.) The terminal velocity of the sabot ranges from 20 to $40 \mathrm{~m} / \mathrm{s}$. The lodging of the nose cone seals the test section from the driver section gases and prevents rebound of the nose cone and out-leakage of the test gases. The experimental data are recorded before, during and after the compression process.

\section{Distinct UM-RCF Design Features}

Several design features of the UM-RCF serve to distinguish the device from other rapidcompression facilities. These features include the large range of compression ratios that can be obtained, the novel sabot design that minimizes fluid disturbances in the test volume, the ability to make temperature measurements at multiple locations within the test volume, and good optical access (see Fig. 3).

The UM-RCF has three elements that can be adjusted to modify the compression ratio. Two extension sections ( $81 \mathrm{~mm}$ and $126 \mathrm{~mm}$ long) can be used (alone or in series) to change the length of the test volume. Two thermocouple sections (16 and $25.4 \mathrm{~mm}$ long) can also be used to modify the test volume. Lastly, the length of the nose cone can be adjusted (from 38 to $89 \mathrm{~mm}$ ) to control how far the nose cone enters the test volume. The combination of these three elements permits the UM-RCF to achieve volumetric compression ratios from 16 to 37.

The design of the sabot is a slight modification (incorporating a change in materials and improvements to sabot balance) of the original TRW design [28] used during their operation of the UM-RCF in the late 1980s. A key feature of the design is the sloped portion of the sabot base (see Figs. 4 and 5). As the sabot travels down the barrel, the motion of the sabot, relative to the walls of the driven section, creates fluid disturbances. In a traditional piston-cylinder arrangement, these fluid disturbances will act to greatly enhance heat transfer in the test volume and drastically reduce the time at which high-temperature combustion conditions can be 
maintained. As shown schematically in Fig. 5, most of the fluid disturbances are effectively captured in the volume between the sloped face of the sabot base and the converging section of the UM-RCF. This greatly reduces induced fluid motion in the test volume and increases the time at which high-temperature conditions persist in the test volume.

The thermocouple manifold permits the simultaneous in situ measurement of gas temperatures at multiple radial locations within the test volume (see Fig. 2). A pair of thermocouple manifolds can be used simultaneously to measure temperature at different axial locations within the test manifold. The ability to make temperature measurements throughout the course of UM-RCF experiments is a valuable experimental tool. Other researchers have used thermocouples to investigate the temperature field in RCFs [18], but these measurements were obtained under limited conditions and were not available for the full duration of reactive experiments (experiments were quenched prior to ignition). Temperature measurements have also been obtained using Rayleigh scattering [9, 17, 18] and laser-induced fluorescence (LIF) [9]. To our knowledge, the use of thermocouples while operating at typical conditions, including with reacting mixtures, is unique to the UM-RCF. Data from the thermocouple measurements can be used to validate modeling of the compression process, provide accurate data on prereaction conditions (temperature need not be inferred from ideal gas or isentropic relations), and can help quantify temperature non-uniformities within the test volume.

Ports in the test section provide optical access to the test volume. This access can be used for various optical diagnostics, including laser absorption spectroscopy, particle scattering, and emission spectroscopy. The steel end wall of the test manifold can be replaced with a polycarbonate window. This window provides excellent optical access to the test volume and permits optical recording of experiments within the UM-RCF. 


\section{Results and Discussion}

To demonstrate the ability of the UM-RCF to generate conditions suited to the study of a wide range of combustion phenomena, a series of experiments were conducted using a mixture of $\mathrm{N}_{2}$ and $\mathrm{O}_{2}$, pure $\mathrm{N}_{2}$, and $\mathrm{Ar}$ as the test gases. In addition to demonstrating the range of test conditions achievable within the UM-RCF, the benchmarking experiments will also show the repeatability of conditions within the UM-RCF. The $\mathrm{N}_{2} / \mathrm{O}_{2}$ mixtures represent the bulk of the gas constituents used in the study of combustion synthesis of $\mathrm{SiO}_{2}$ nanoparticles. The experiments with $\mathrm{N}_{2}$ as a test gas are proxies for the conditions typical of hydrocarbon ignition. The Ar mixtures generate test conditions that would be suited to the study of very high temperature combustion phenomena and demonstrate the range of capabilities of the UM-RCF. Non-reactive mixtures are used for all performance benchmark experiments for two reasons. First, fundamental RCF performance is easier to quantify in the absence of chemical reaction. Second, in the planned combustion experiments, reactants are only expected to make up a small fraction of the test gas mixtures (mole fractions of $<2 \%$ ). Ar, $\mathrm{N}_{2}$, and $\mathrm{O}_{2}$ are the bulk of the gas constituents in the mixtures, and therefore the behavior of these gases will strongly determine the behavior of the overall test gas mixtures.

Figure 6 presents a typical pressure/temperature time-history from an $\mathrm{N}_{2} / \mathrm{O}_{2}$ mixture experiment in the UM-RCF. The initial pressure $\left(P_{\mathrm{o}}\right)$ of the mixture in the driven section was $3.37 \mathrm{kPa}$ ( 25.3 torr) and the mixture was $95.9 \% \mathrm{~N}_{2}$, on a mole basis, with the balance being $\mathrm{O}_{2}$. The peak experimental temperature $\left(T_{\max }\right)$ and pressure $\left(P_{\max }\right)$ observed were $965 \mathrm{~K}$ and $219 \mathrm{kPa}$, respectively. Figures 7 and 8 present similar pressure/temperature time-histories for experiments with $\mathrm{N}_{2}\left(P_{\mathrm{o}}=26.7 \mathrm{kPa}, T_{\max }=971 \mathrm{~K}, P_{\max }=1940 \mathrm{kPa}\right)$ and $\operatorname{Ar}\left(P_{\mathrm{o}}=6.01 \mathrm{kPa}, T_{\max }=1996 \mathrm{~K}\right.$, $\left.P_{\max }=774 \mathrm{kPa}\right)$ as the test gases. All experimental data in Figs. 6 to 8 have been filtered to 
remove high frequency $(>1 \mathrm{kHz})$ noise. Additionally, the temperature data have been processed to account for the time response of the thermocouples and include corrections for radiation heat transfer. The thermocouple data processing is discussed in further detail below. Included in Fig. 6 are the raw pressure and temperature data obtained at the end of the compression event. The raw data provide an indication of the typical level of disturbances observed in the data. Several features are worth noting regarding Figs. 6 to 8:

- The bulk (80\%) of the pressure rise and the majority (50\%) of the temperature rise occur in a very short time ( $<10$ milliseconds). This quick compression minimizes the cooling of the test gas mixture at the walls of the UM-RCF.

- The compression process occurs smoothly, without any significant pressure disturbances prior to seating of the sabot in the extension section. The final impact of the sabot into the test manifold does create some small pressure disturbances (see inset figure of Fig. 6). As noted above, these high frequency (>1 kHz) disturbances generated by the impact are filtered from the data. The source and magnitude of these pressure disturbances are discussed in more detail below.

- Combustion conditions (pressure $>75 \% P_{\max }$, temperature $>80 \% T_{\max }$ ) are maintained in the test manifold for approximately $50 \mathrm{~ms}$ or longer depending on the test conditions and composition of the test gas mixture.

- Cooling of the test gases occurs gradually over time (as seen in the pressure data), without any sharp changes that would indicate greatly enhanced heat transfer due to large-scale fluid motion.

- Unsteadiness in the temperature trace (at long times, $t>20 \mathrm{~ms}$ ) is primarily attributable to motion of the thermocouple. The location of the thermocouple bead 
fluctuates slightly within the test volume due to fluid motion and thermal expansion of the thermocouple wires, leading to variation in the measured temperature. This thermocouple motion has been observed via high speed imaging through the transparent end wall.

Figure 9 shows the results of four UM-RCF experiments (including data from Fig. 6) using an $\mathrm{N}_{2} / \mathrm{O}_{2}$ mixture as the test gas, each with initial pressures of approximately $3.4 \mathrm{kPa}(25.3$ torr). Figure 10 shows a similar set of four UM-RCF experiments (including the data from Fig. 8) conducted using Ar as the test gas. In each of these experiments, the initial Ar pressure is approximately $6 \mathrm{kPa}$ (45 torr).

Figures 9 and 10 demonstrate the UM-RCF is capable of generating very repeatable test conditions. The variability in peak pressures is within $3 \%$ for both sets of data, and in both sets of data the individual pressure histories follow nearly identical trajectories. The small differences observed in the individual pressure histories can be readily attributed to run-to-run uncertainties in initial pressures, drive pressures, frictional forces, and fluid behavior. As with the pressure histories, the temperature histories follow nearly identical trajectories during the compression process. The divergence in the temperature histories after this point is primarily due to the limitation of the methodology used to correct for the time response of the thermocouples. This is addressed in further detail below.

\section{Data Post-Processing}

As noted above, the experimental data are post-processed. The impact of the sabot into the test manifold creates pressure disturbances that are filtered from the data. Spectral analysis of these disturbances indicates the frequencies of the disturbances are consistent with the frequencies at which pressure waves traverse the test volume. These disturbances are not believed to be 
representative of the mean pressure in the test manifold and are thought to be due to vibrations created in the test manifold due to the forceful impact of the sabot into the test manifold. The average magnitude of these disturbances is less than $3 \%$ of the peak pressure, with the maximum disturbance being less than $10 \%$. The magnitude of the disturbances correlates strongly with the force of the impact of the sabot into the test manifold.

The raw data from the $25 \mu \mathrm{m}$ diameter thermocouples $(\sim 80 \mu \mathrm{m}$ bead diameter) are postprocessed to remove high-frequency electrical noise. The temperature measurements are also corrected to account for radiation heat transfer and the time response of the thermocouples. Due to their thermal mass, the temperature measured by the thermocouples lags the actual gas temperature. Failure to make this correction results in an under-prediction of peak temperatures and temperature profiles which are temporally displaced from the actual gas temperatures. The actual gas temperature $\left(T_{\mathrm{g}}\right)$ is related to the measured temperature $T_{\mathrm{m}}$ by the relation $T_{\mathrm{g}}=T_{\mathrm{m}}+\tau \frac{d T_{\mathrm{m}}}{d t}+\frac{\varepsilon \sigma}{\bar{h}}\left(T_{m}^{4}-T_{w}^{4}\right)$, where the time constant of the thermocouple is $\tau=\frac{\rho c d^{2}}{4 k \cdot N \dot{u}}($ where $\rho, c$ and $d$ are the density, heat capacity and diameter of the thermocouple wire, respectively, $k$ is the thermal conductivity of the gas, and $N u$ is the Nusselt number), the emissivity of the thermocouple is $\varepsilon$, the average heat transfer coefficient is $\bar{h}$, and the temperature of the RCF walls is $T_{w}$. The time responses of the thermocouples vary based on experimental conditions, primarily due to differences in gas properties (density, thermal conductivity, and viscosity) and gas velocity, which affects the Nusselt number. The thermocouple time response is also a function of time, as the parameters on which it is based vary during the course of the compression process. 
For the data presented here, the thermocouple time constants are determined individually for each experiment. The time constant is calculated based on instantaneous gas properties (temperature, density, etc.) and standard correlations for convective heat transfer to a sphere. Based on these calculations, the uncertainty in the corrected temperature during compression is estimated to be $\pm 5 \%$. Uncertainties at times after the point of peak pressure are expected to be greater because the thermocouple correction model does not accurately represent the actual fluid dynamics within the test volume after the sabot nose cone has come to rest.

\section{Experimental Modeling}

Analytical models that can be used to predict RCF performance (peak temperature and pressure) for a given set of operating conditions are valuable aids to the design of experiments using RCFs. Because compression of the test gases is rapid (the entire compression process occurs in approximately $100 \mathrm{~ms}$, with the bulk of the compression occurring in the last $10 \mathrm{~ms}$ ), as a first approximation the compression process can be considered to occur isentropically. Modeling the compression as an isentropic process provides an upper bound on the temperature and pressure that can be generated by the UM-RCF for non-reacting test gas mixtures.

Using the isentropic relations for an ideal gas, the pressure and temperature depend only on the compression ratio $(C R)$ and the ratio of the specific heats of the compressed gas mixture $\left(\gamma=C_{\mathrm{p}} / C_{\mathrm{v}}\right)$, where $C R$ is defined as the ratio of the initial molar specific volume $\left(\bar{v}_{\mathrm{o}}\right)$ to the molar specific volume at the end of compression $\left(\bar{v}_{\max }\right)$. With $P_{\mathrm{o}}$ and $T_{\mathrm{o}}$ as the initial pressure and temperature, the peak pressure and temperature $\left(P_{\max }\right.$ and $T_{\max }$, respectively) can be calculated using the following relations:

$$
\int_{P_{\mathrm{o}}}^{P_{\max }} \frac{1}{\gamma} d \ln P=\ln \frac{\bar{v}_{\mathrm{o}}}{\bar{v}_{\max }}=\ln C R
$$




$$
\int_{T_{\mathrm{o}}}^{T_{\max }} \frac{1}{\gamma-1} d \ln T=\ln \frac{\bar{v}_{\mathrm{o}}}{\bar{v}_{\max }}=\ln C R
$$

For a non-monatomic gas, Eqns (1) and (2) must be solved by direct integration. For the case of a monatomic test gas, $\gamma$ is a constant and Eqns (1) and (2) simplify to:

$$
\begin{gathered}
\frac{P_{\max }}{P_{\mathrm{o}}}=C R^{\gamma} \\
\frac{T_{\max }}{T_{\mathrm{o}}}=C R^{\gamma-1}
\end{gathered}
$$

Adopting an appropriate average value for $\gamma$, Eqns (3) and (4) may be applied to nonmonatomic gases. While Eqns (3) and (4) are not used for the analysis of the UM-RCF data presented in the current work (with the exception of experiments with argon as the test gas), they do provide a convenient method for the evaluation of isentropic conditions for non-monatomic gases and will be used here to simplify the discussion of the compression process.

Two issues arise in the use of Eqns (3) and (4) to model the compression process in the UM-RCF: what is the appropriate compression ratio and is the compression process truly isentropic? Defining the compression ratio is not straightforward with the UM-RCF. In a typical control mass piston-cylinder arrangement, the compression ratio would be defined simply as the ratio of the initial (pre-compression) volume to the final (post-compression) volume. With the UM-RCF, the stepped nature of the "cylinder" and "piston" along with the possibility of mass outflow from the test volume (past the U-ring seals and into the driver gases) complicate using such a definition for the compression ratio.

To deal with the difficulty of defining a compression ratio in the traditional sense, an effective compression ratio $\left(C R^{\prime}\right)$ was defined based on the ratio of the post-test pressure to the initial pressure. As will be shown below, this compression ratio is the same ratio as used in Eqns (1) to (4); it is just calculated differently. Using the ideal gas equation of state (where $P$ is the 
pressure, $V$ is the volume, $n$ is number of moles, and $T$ is the absolute temperature), the ratio of the pressure at a sufficiently long time after compression, $P_{\mathrm{f}}$, to the initial pressure, $P_{\mathrm{o}}$ is:

$$
\frac{P_{\mathrm{f}}}{P_{\mathrm{o}}}=\frac{n_{\mathrm{f}} T_{\mathrm{f}} V_{\mathrm{o}}}{n_{\mathrm{o}} T_{\mathrm{o}} V_{\mathrm{f}}}=\frac{\bar{v}_{\mathrm{o}}}{\bar{v}_{\mathrm{f}}} \frac{T_{\mathrm{f}}}{T_{\mathrm{o}}}
$$

If the temperatures of initial and final states are identical (as they are prior to the start of compression and long after the compression process is completed), temperature can be eliminated from Eqn (5) and the ratio of the final pressure to initial pressure is given as:

$$
\frac{P_{\mathrm{f}}}{P_{\mathrm{o}}}=\frac{\bar{v}_{\mathrm{o}}}{\bar{v}_{\mathrm{f}}}=C R^{\prime}
$$

For a non-reacting mixture, the volume and number of moles does not change between the end of compression and some final state long afterward $\left(\bar{v}_{\max }=\bar{v}_{\mathrm{f}}\right)$, and the pressure ratio in Eqn (6) is the same as the compression ratio used in Eqns (1) to (4), i.e $C R=C R^{\prime}$. To use Eqn (6) with a reacting mixture, one must account for the change in the specific molar volume that occurs between the end of compression and the final state $\left(\bar{v}_{\mathrm{f}}=\frac{n_{\max }}{n_{\mathrm{f}}} \bar{v}_{\max }\right)$.

As can be seen from Eqn (5), this definition of the compression ratio accounts for any mass lost from the system during compression (such losses are isentropic as far as the remaining control mass is concerned) and allows the determination of compression ratio by a simple ratio of pressure measurements as opposed to much more complicated volume measurements. Eqns (1), (2) and (6) have been applied to the data shown in Figs. 7, 9, and 10 and the results are presented in Table 1.

The results in Table 1 show that using an isentropic model of the compression process yields predicted pressures and temperatures that are higher than the measured pressures and temperatures. This is to be expected, as non-ideal aspects of the compression process (primarily heat transfer from the gases to the walls of the UM-RCF) cause the realized temperatures and 
pressures to depart from those predicted by an isentropic analysis. Worth noting is how the accuracy of the isentropic model depends on the test gas mixture and the test conditions. Since heat transfer to the walls is proportional to $k_{\mathrm{f}} / \rho_{\mathrm{f}} C_{\mathrm{p}, \mathrm{f}}$ (where $k_{\mathrm{f}}, \rho_{\mathrm{f}}$ and $C_{\mathrm{p}, \mathrm{f}}$ are the thermal conductivity, density, and the constant pressure heat capacity of the gas, respectively), it is reasonable to expect a gas mixture with a higher density and heat capacity to be less affected by cooling at the walls. As heat transfer to the walls is also proportional to the temperature difference between the bulk gas and the walls, a cooler gas will lose heat at a lower rate to the walls. These conclusions are supported by the results of Table 1 where the over-prediction of pressure is $6 \%$ for $\mathrm{N}_{2}$ as the test gas $\left(\rho_{\mathrm{f}} C_{\mathrm{p}, \mathrm{f}}=8250 \mathrm{~J} / \mathrm{m}^{3}-\mathrm{K}, \Delta T \approx 690 \mathrm{~K}\right), 13 \%$ for the $\mathrm{N}_{2} / \mathrm{O}_{2}$ mixtures $\left(\rho_{\mathrm{f}} C_{\mathrm{p}, \mathrm{f}}=1000, \Delta T \approx 645 \mathrm{~K}\right)$, and $24 \%$ for argon as the test gas $\left(\rho_{\mathrm{f}} C_{\mathrm{p}, \mathrm{f}}=1080 \Delta T \approx 1700\right.$ $\mathrm{K})$. For these calculations, $\rho_{\mathrm{f}}$ is determined from the final temperature and pressure, $C_{\mathrm{p}, \mathrm{f}}$ is calculated at the peak temperature, and $\Delta T$ is the difference between the maximum gas temperature and the wall temperature. (It should be noted that the difference in $\rho_{\mathrm{f}} C_{\mathrm{p}, \mathrm{f}}$ between the $\mathrm{N}_{2}$ and the $\mathrm{N}_{2} / \mathrm{O}_{2}$ mixtures is due largely to the differences in the density which are due to the different initial pressures of these two mixtures: 26.7 and $3.37 \mathrm{kPa}$, respectively.) The thermal conductivity, $k_{\mathrm{f}}$, is roughly identical for all the gas mixtures and is therefore omitted for clarity. The $\mathrm{N}_{2}$ experiment has the highest $\rho_{\mathrm{f}} C_{\mathrm{p}, \mathrm{f}}$ and nearly the lowest temperature differential. Therefore, it is not surprising to find the $\mathrm{N}_{2}$ experimental results are best modeled with an isentropic analysis. The $\mathrm{N}_{2} / \mathrm{O}_{2}$ and Ar data sets have nearly identical values of $\rho_{\mathrm{f}} C_{\mathrm{p}, \mathrm{f}}$, yet the argon experiments have a temperature difference over 2.5 times that of the $\mathrm{N}_{2} / \mathrm{O}_{2}$ experiments. This difference between the $\mathrm{N}_{2} / \mathrm{O}_{2}$ and Ar data is reflected in how well the data are represented by the isentropic analysis. Despite the shortcomings of an isentropic model, this model can still provide valuable insights into the compression process. 
While the overall compression process is non-isentropic, is it realistic to assume that a core region of the compressed gas is unaffected by heat transfer at the walls and is compressed in an isentropic manner as suggested by other RCF researchers [29]. Having such a core region is necessary to support the assumption that conditions within the (reacting) gas mixture can be treated as (spatially) uniform. If non-isentropic effects, such as heat transfer and fluid motion, were significant throughout the test gas volume, analysis and interpretation of RCF results would be extremely difficult. As discussed previously, the rapid compression times (that minimize heat transfer to the RCF walls) and the novel sabot design (that minimizes the effects of the boundary layers on the bulk of the gas mixture) are features of the UM-RCF that are expected to promote the existence of a core region which is compressed in an essentially isentropic manner. Confirming the existence of this "isentropic core" then becomes a matter of a thermodynamic calculation.

Based on the initial and maximum pressures $\left(P_{\mathrm{o}}\right.$ and $\left.P_{\max }\right)$, an effective compression ratio $\left(C R_{\text {eff }}\right)$ can be calculated for the core gas region by using the measured pressure time history, a temperature-dependant expression for $\gamma$, and numerically integrating Eqn (1). Due to the effects of heat transfer on the pressure of the test gases, $C R_{\text {eff }}$ will naturally be lower than the physical compression ratio determined using Eqn (6). Using this effective compression ratio, the maximum gas temperature can be calculated and compared to the measured gas temperature as a check on the accuracy of the measurement and the validity of the assumption of an isentropic gas core region. For argon the process is much simpler as $\gamma$ is independent of temperature and the $T_{\max }$ can be calculated directly by combining Eqns (3) and (4) to yield: $T_{\max }=T_{\mathrm{o}}\left(P_{\max } / P_{\mathrm{o}}\right)^{(\gamma-1) / \gamma}$. These calculations have been applied to the data of Table 1 and the results are shown in Table 2 . 
As can be seen in Table 2, the predicted maximum temperatures are in very good agreement with the measured temperatures (less than $5 \%$ difference for all conditions studied), supporting the assumption of an "isentropic core." Negative differences between the model predictions and the measured temperatures are an indication of the limitations of the thermocouple measurements. Additionally, this technique can be applied to mixtures that react subsequent to the compression process. The comparison between measured and calculated maximum temperatures can also be used to determine if reaction occurs during the compression process.

\section{Temperature Distribution in the UM-RCF}

While the existence of an isentropic core has been demonstrated, the extent of this core region is unclear. For the assumption of an isentropic core to be useful for experimental studies, the radial and axial extent of this region must be quantified. Based on the previous calculations, it is reasonable to assume the isentropic core region encompasses the volume in which the temperature is approximately that measured by the center thermocouple. To determine the extent of this core region, simultaneous radial and axial temperature measurements were obtained at several locations in the test manifold.

Radial temperature profiles were obtained using a thermocouple manifold equipped with four thermocouples. The nominal locations of the thermocouple junctions were the center ( $25.4 \mathrm{~mm}$ from the wall), $0.9 \mathrm{~mm}$ from the wall, and two intermediate locations. Two pairs of intermediate locations were investigated: 2.9 and $10.4 \mathrm{~mm}$ from the wall and 5 and $7 \mathrm{~mm}$ from the wall. Figures 11 and 12 present the temperature measurements from these two experiments (all using nitrogen as the test gas) conducted using this thermocouple manifold. The measured thermocouple temperatures were corrected as previously described. Data from the thermocouple 
located at $0.9 \mathrm{~mm}$ from the wall have been omitted due to difficulty in accounting for the complex fluid flow near the wall when correcting the measured temperature obtained from this thermocouple. Due to the nature of the fluid dynamics within the test volume after the point of peak pressure (time $=0$ ), the uncertainties in the corrected temperatures increase substantially after $t=0 \mathrm{~s}$. Therefore, for $t>0 \mathrm{~s}$, the corrected data should be considered a qualitative representation of the radial temperature profile.

As can be seen in Fig. 11, the temperature measured $10.4 \mathrm{~mm}$ from the test manifold wall is essentially identical to the temperature measured at the center of the test manifold for the duration of the data presented. Additionally, from Fig. 11 it is evident that the temperature measured $2.9 \mathrm{~mm}$ from the wall deviates substantially from the temperature measured at the center: a clear indication that the cooling effects at the wall are affecting the gas at this location. The temperatures at $7 \mathrm{~mm}$ from the wall and $5 \mathrm{~mm}$ from the wall (Fig. 12) depart from the temperature measured at the center, but the magnitude of the departure is significantly less than that observed at $2.9 \mathrm{~mm}$. As a quantitative measure of the extent of the isentropic core, the $T_{90}$ temperature was selected:

$$
T_{90}=0.9 \cdot\left(T_{\mathrm{c}}-T_{\mathrm{w}}\right)+T_{\mathrm{w}}
$$

where $T_{\mathrm{c}}$ is the temperature at the center thermocouple and $T_{\mathrm{w}}$ is the wall temperature, $T_{\mathrm{w}} \approx 298$ K. The $T_{90}$ temperature has been plotted in Figs. 11 and 12. Based on the experimental data, the $T_{90}$ temperature boundary is located at approximately $7.5 \mathrm{~mm}$ from the wall. Based on this distance, the radial extent of the "isentropic core" is $70 \%$ of the radius of the test volume and $50 \%$ of the cross-sectional area.

Axial variations in temperature were investigated by installing two thermocouple manifolds separated by an extension section. The axial separation between the two sets of 
thermocouples was $106 \mathrm{~mm}$. The experiments were conducted with nitrogen as the test gas at conditions similar to those in Fig. 6. Figure 13 presents a typical data set from these investigations. As can be seen from the figure, there are negligible differences between the temperatures at the two axial locations. The small differences seen post-compression $(t>0 \mathrm{~s})$ are more due to uncertainties with the temperature correction technique (discussed previously) than differences in the thermocouple measurements. Based on these data, axial variations in temperature within the test volume (away from the end wall and the sabot) are considered negligible within the time frame of the experiments.

\section{Reactive Mixture Experiment}

As a further demonstration of the capabilities of the UM-RCF, the results of an early investigation into iso-octane ignition are presented in Fig. 14. The test gas mixture for this experiment was $0.53 \% \mathrm{C}_{8} \mathrm{H}_{18}, 16.59 \% \mathrm{O}_{2}, 10.01 \% \mathrm{Ar}$, and balance $\mathrm{N}_{2}$ (equivalence ratio $\approx 0.4$ ). The initial pressure was $18.1 \mathrm{kPa}$ (136 torr) and the nominal calculated compression ratio (CR ) was 26.1. In addition to the pressure data, Fig. 14 includes emission recorded by an un-amplified silicon photodiode detector (Hamamatsu S1787-3).

The measured pressure at the end of the compression process is $1630 \mathrm{kPa}$. Using this pressure and the initial pressure of $18.1 \mathrm{kPa}$ in Eqn. (6), the isentropic core temperature (prior to reaction) is calculated to be $991 \mathrm{~K}$. As can also be seen in Fig. 14, the start of the emission signal corresponds extremely well with the increase in pressure due to ignition. The calculated ignition delay time is approximately $8 \mathrm{~ms}$. The iso-octane ignition data serve to demonstrate the potential of the UM-RCF for studies of reacting mixtures using the conditions and performance validated by the non-reacting studies. 


\section{Conclusions}

The current work demonstrates the suitability of the UM-RCF as an experimental tool for the study of combustion phenomena. As can be seen in Table 3, the experimental conditions that can be achieved with the UM-RCF expand the envelope of RCF operating conditions, which increases the usefulness of the RCF as a research tool. The diagnostics available with the UMRCF (pressure, temperature, optical diagnostics, and high speed video capture) also expand the range of data that can be obtained from RCF experiments.

The characterization data show that the UM-RCF can rapidly generate and sustain the high temperatures and pressures found in many combustion systems of interest. The high temperature (greater than $80 \% T_{\max }$ ) and high pressure (greater than $75 \% P_{\max }$ ) test conditions can be maintained for durations substantially longer than those obtainable with shock tubes or demonstrated by other rapid-compression facilities (i.e. $50 \mathrm{~ms}$ and greater, depending on the test gas densities and heat capacities). The data show excellent test repeatability, with a run-to-run variability of less than $3 \%$ (based on pressure measurements). Analysis of the data indicates the existence of a core region of the test gas which is compressed isentropically and has nominally uniform conditions. This core region extends across $70 \%$ of the diameter of the test section and contains approximately $50 \%$ of the test gas volume. Existence of such a region is essential to maximizing the utility of the UM-RCF as a combustion research tool. These beneficial aspects of the state conditions found in the UM-RCF experiments are direct results of the unique design of the UM facility. The high pressures, moderate temperatures, and long test times make the UM-RCF an ideal facility to complement other chemical reactor studies. 
Table 1 Measured pressures, temperatures ${ }^{\mathrm{a}}$ and equivalent compression ratios $\left(C R^{\prime}\right)$ for the data from Figs. 6, 8, and 9 along with maximum calculated pressures and temperatures (based on $C R^{\prime}$ ).

\begin{tabular}{lcccccccccc}
\hline & & & & & \multicolumn{3}{c}{$P_{\max }(\mathrm{kPa})$} & \multicolumn{3}{c}{$T_{\max }(\mathrm{K})$} \\
\cline { 8 - 12 } Mix. & Run & $P_{\mathrm{o}}(\mathrm{kPa})$ & $P_{\mathrm{f}}(\mathrm{kPa})$ & $C R^{\prime}$ & Meas. & Calc. & \%Diff & Meas. $^{\text {a }}$ & Calc. & $\%$ Diff \\
\hline \multirow{2}{*}{$\mathrm{N}_{2} / \mathrm{O}_{2}$} & 1 & 3.42 & 77.0 & 22.5 & 224 & 251 & 12.0 & 935 & 969 & 3.6 \\
& 2 & 3.35 & 76.7 & 22.9 & 223 & 252 & 13.0 & 922 & 975 & 5.7 \\
& 3 & 3.37 & 75.6 & 22.4 & 219 & 246 & 12.3 & 965 & 966 & 0.1 \\
\hline $\mathrm{N}_{2}$ & 4 & 3.36 & 75.8 & 22.6 & 220 & 248 & 12.7 & 929 & 969 & 4.3 \\
\hline & 1 & 26.7 & 622 & 23.3 & 1940 & 2060 & 6.2 & 971 & 981 & 1.0 \\
$\mathrm{Ar}$ & 1 & 6.16 & 128 & 20.9 & 784 & 973 & 24.1 & 2008 & 2246 & 11.9 \\
& 2 & 6.01 & 126 & 21.0 & 774 & 963 & 24.4 & 1996 & 2254 & 12.9 \\
& 3 & 6.04 & 128 & 21.2 & 786 & 984 & 25.2 & 2006 & 2270 & 13.2 \\
& 4 & 6.05 & 128 & 21.2 & 793 & 985 & 24.2 & 1995 & 2269 & 13.7 \\
\hline
\end{tabular}

${ }^{a}$ Temperatures are the corrected readings from the thermocouple located at the nominal (radial) center of the test volume.

Table 2 Measured pressures and temperatures ${ }^{\mathrm{a}}$, calculated effective compression ratios $\left(C R_{\text {eff }}\right)$, and maximum calculated temperatures (based on $C R_{\text {eff }}$ ) for the data from Figs. 6, 8, and 9.

\begin{tabular}{lccccccc}
\hline & & & & & \multicolumn{3}{c}{$T_{\max }(\mathrm{K})$} \\
\cline { 6 - 8 } Mixture & Run & $P_{\mathrm{o}}(\mathrm{kPa})$ & $P_{\max }(\mathrm{kPa})$ & $C R_{\text {eff }}$ & Measured $^{\mathrm{a}}$ & Calc. & $\%$ Diff \\
\hline \multirow{2}{*}{$\mathrm{N}_{2} / \mathrm{O}_{2}$} & 1 & 3.42 & 224 & 20.7 & 935 & 942 & 0.7 \\
& 2 & 3.35 & 223 & 20.9 & 922 & 945 & 2.5 \\
& 3 & 3.37 & 219 & 20.5 & 965 & 937 & -2.9 \\
\hline $\mathrm{N}_{2}$ & 4 & 3.36 & 220 & 20.7 & 929 & 939 & 1.1 \\
\hline \multirow{3}{*}{$\mathrm{Ar}$} & 1 & 26.7 & 1940 & 22.3 & 971 & 965 & -0.6 \\
& 1 & 6.16 & 784 & 18.3 & 2008 & 2061 & 2.6 \\
& 2 & 6.01 & 774 & 18.4 & 1996 & 2066 & 3.5 \\
& 3 & 6.04 & 786 & 18.6 & 2006 & 2075 & 3.4 \\
& 4 & 6.05 & 793 & 18.6 & 1995 & 2081 & 4.3 \\
\hline
\end{tabular}

a Temperatures are the corrected readings from the thermocouple located at the nominal (radial) center of the test volume.

Table 3 Brief summary of RCF experimental conditions reported in the literature. Pressures and temperatures are the maximum reported values without reaction.

\begin{tabular}{lcccc}
\hline \multicolumn{1}{c}{ Facility } & & $T_{\max }(\mathrm{K})$ & $\begin{array}{c}\text { Compression } \\
\text { Ratio }\end{array}$ & $\begin{array}{c}\text { Compression } \\
\text { Time }(\mathrm{ms})\end{array}$ \\
\hline University of Michigan & $>2000$ & $1000\left(\mathrm{~N}_{2}\right)$ & $16-37$ & $\sim 100$ \\
Leeds University & 2000 & $2000(\mathrm{Ar})$ & & \\
UST at Lille & 1700 & 9000 & $<14.6$ & 22 \\
MIT & 7000 & 1200 & $\sim 10$ & $20-60$ \\
University of Ireland, Galway & 4000 & 1060 & 19 & $10-30$ \\
\hline
\end{tabular}


Fig. 1 Schematic and photograph of the University of Michigan Rapid Compression Facility.

Fig. 2 End view of the thermocouple manifold showing typical placement of two fine wire thermocouples.

Fig. 3 Cross-sectional view of the UM-RCF test section. Optical and instrument ports are shown with the ports removed.

Fig. 4 Photograph of the UM-RCF sabot. The black portion is the Delrin ${ }^{\mathrm{TM}}$ body and the white portion

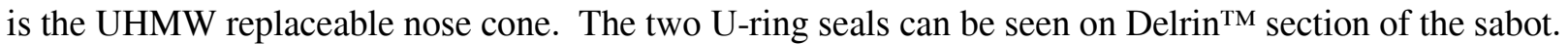
Fig. 5 Depiction of the UM-RCF in operation. a) Driven section is charged with the test gas mixture prior to start of test. Driver section is charged with high-pressure air. b) Hydraulic valve is opened and high-pressure gas from the driver section propels the sabot down the length of the driven section. c) Sabot travels down the length of the driven section, compressing the test gas mixture ahead of the sabot. d) Sabot is lodged in the extension section, trapping the test gas mixture within the test manifold. The annular region of the test gas mixture, which includes most of the fluid disturbances caused by the travel of the sabot down the length of the driven section, is trapped in the shoulder region.

Fig. 6 Typical pressure and temperature time-histories from an UM-RCF experiment using an $\mathrm{N}_{2} / \mathrm{O}_{2}$ mixture as the test gas $\left(95.9 \% \mathrm{~N}_{2}\right.$, balance $\left.\mathrm{O}_{2}\right), P_{\mathrm{o}}=3.37 \mathrm{kPa}$. The inset shows raw pressure and temperature traces.

Fig. 7 Typical pressure and temperature time-histories from an UM-RCF experiment using $\mathrm{N}_{2}$ as the test gas, $P_{\mathrm{o}}=26.7 \mathrm{kPa}$.

Fig. 8 Typical pressure and temperature time-histories from an UM-RCF experiment using Ar as the test gas, $P_{\mathrm{o}}=6.01 \mathrm{kPa}$.

Fig. 9 Four UM-RCF experiments using an $\mathrm{N}_{2} / \mathrm{O}_{2}$ mixture as the test gas, which demonstrate experimental repeatability. Mixtures were $95.9 \% \mathrm{~N}_{2}$ and each experiment had a nominal initial pressure 
of $3.4 \mathrm{kPa}$. Dashed lines are center thermocouple data (corrected). Solid lines are pressure transducer data.

Fig. 10 Four UM-RCF experiments using Ar as the test gas, which demonstrate experimental repeatability. Each experiment had a nominal initial pressure of $6.0 \mathrm{kPa}$. Dashed lines are center thermocouple data (corrected). Solid lines are pressure transducer data.

Fig. 11 Corrected temperature profiles measured at three radial locations for an UM-RCF experiment with $\mathrm{N}_{2}$ as the test gas, $P_{\mathrm{o}}=3380 \mathrm{~Pa}$. The thermocouples were located $25.4 \mathrm{~mm}$ (center, dashed line), $10.4 \mathrm{~mm}$ (dash-dotted line), and $2.9 \mathrm{~mm}$ (dotted line) from the wall of the thermocouple manifold. The $T_{90}$ temperature, Eqn (7), is indicated by the solid line.

Fig. 12 Corrected temperature profiles measured at three radial locations for an UM-RCF experiment with $\mathrm{N}_{2}$ as the test gas, $P_{\mathrm{o}}=4560 \mathrm{~Pa}$. The thermocouples were located $25.4 \mathrm{~mm}$ (dashed line), $7 \mathrm{~mm}$ (dash-dotted line), and $5 \mathrm{~mm}$ (dotted line) from the wall of the thermocouple manifold. The $T_{90}$ temperature, Eqn (7), is indicated by the solid line.

Fig. 13 Corrected temperature profiles at two axial locations for an UM-RCF experiment with $\mathrm{N}_{2}$ as the test gas, $P_{\mathrm{o}}=4560 \mathrm{~Pa}$. The thermocouples were located at the radial center of the test manifold and at $64 \mathrm{~mm}$ (dashed line) and 170 (solid line) $\mathrm{mm}$ from the end wall.

Fig. 14 Typical pressure (solid line) and light-emission (dashed line) time-histories from an UM-RCF experiment using $\mathrm{C}_{8} \mathrm{H}_{18} / \mathrm{O}_{2} / \mathrm{Ar} / \mathrm{N}_{2}$ (mole fractions of $0.0053,0.1659,0.1001$, respectively, balance $\mathrm{N}_{2}$ ) as the test gas, $P_{\mathrm{o}}=18.1 \mathrm{kPa}$. 


\section{Test Manifold}

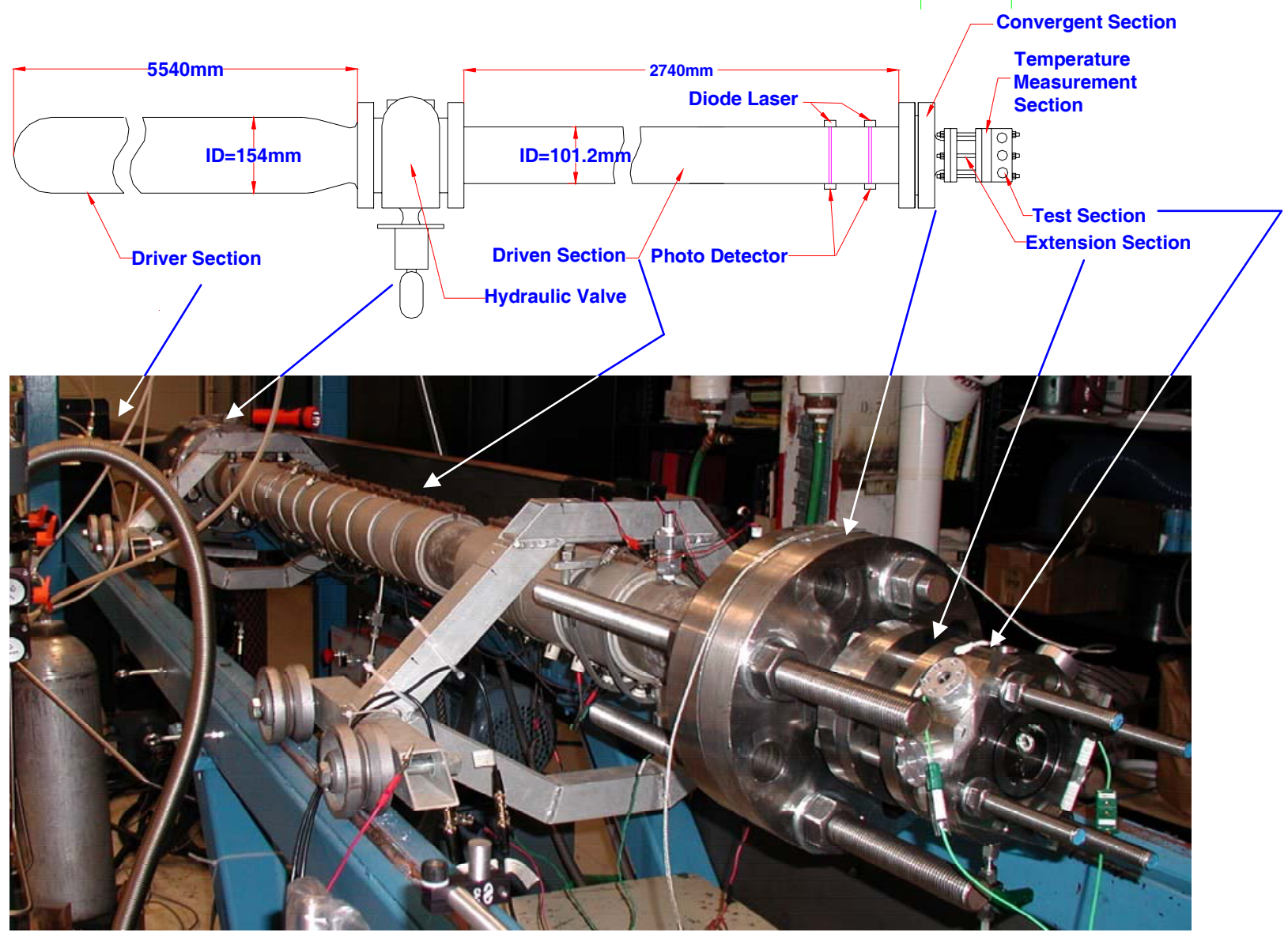

Fig. 1 Schematic and photograph of the University of Michigan Rapid Compression Facility. 


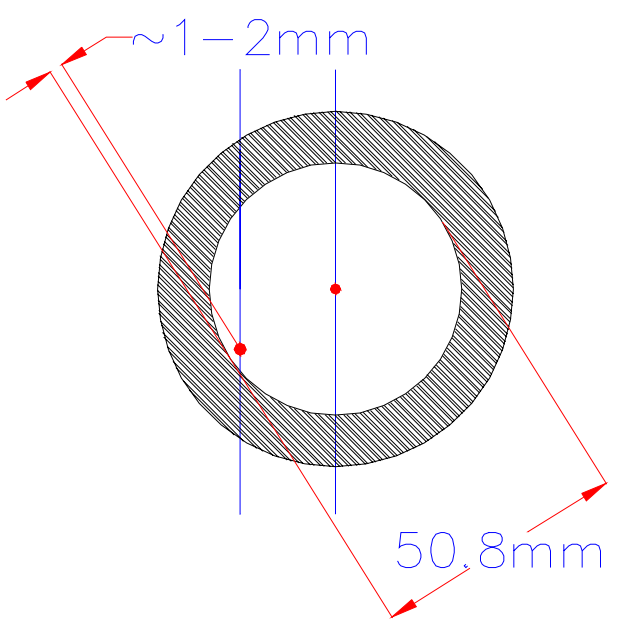

Fig. 2 End view of the thermocouple manifold showing typical placement of two fine wire thermocouples. 


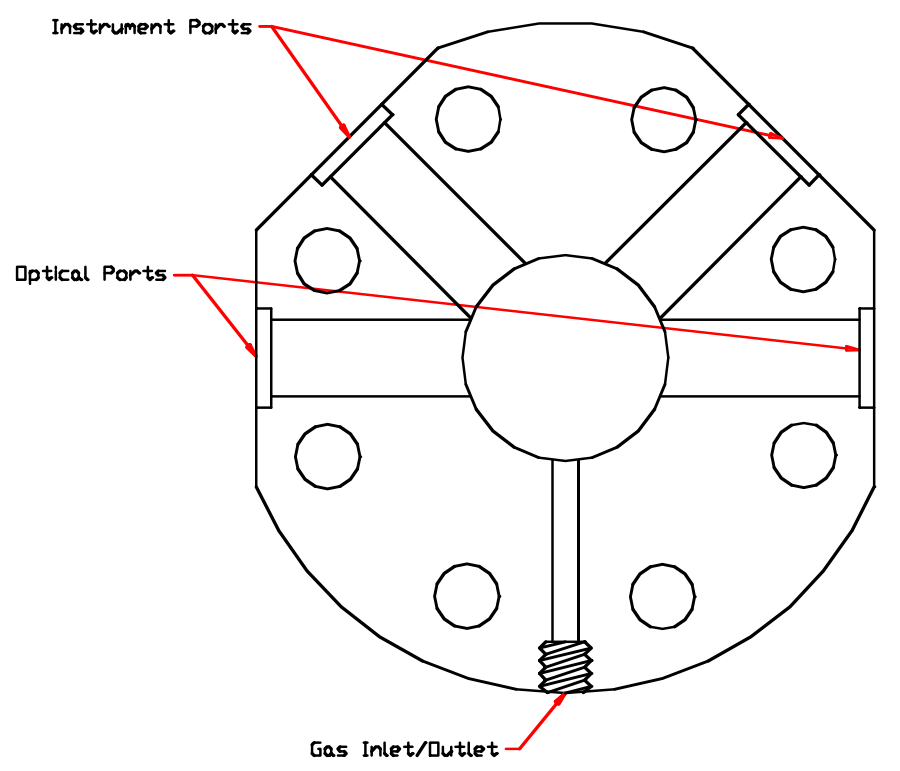

Fig. 3 Cross-sectional view of the UM-RCF test section. Optical and instrument ports are shown with the ports removed. 


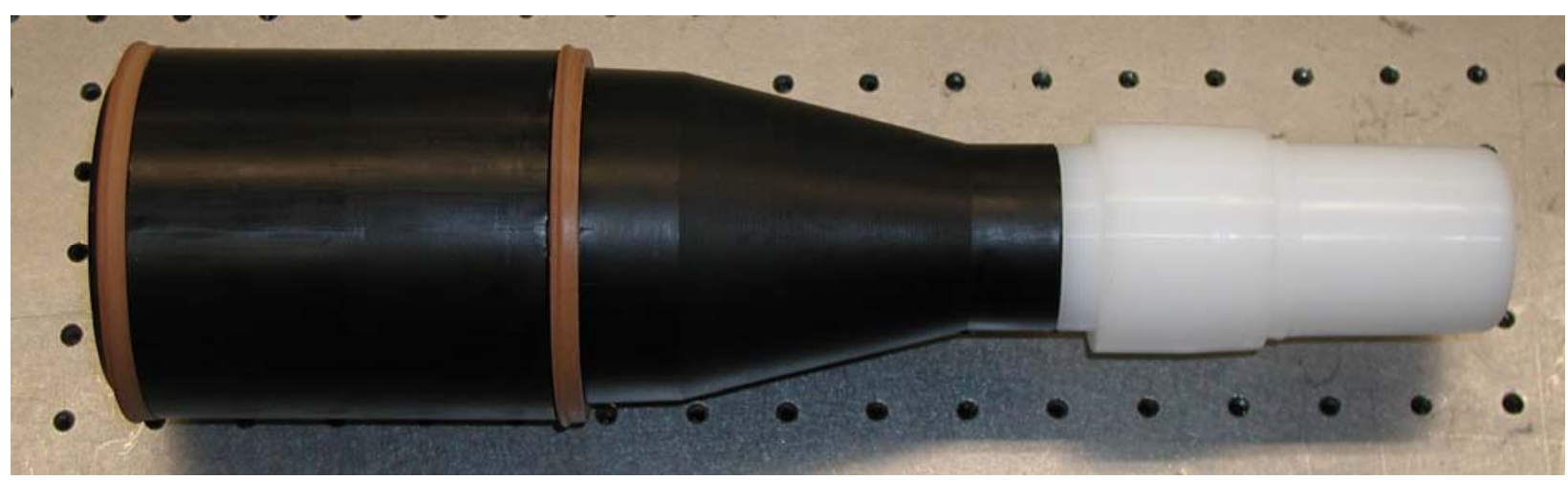

Fig. 4 Photograph of the UM-RCF sabot. The black portion is the Delrin ${ }^{\mathrm{TM}}$ body and the white portion is the UHMW replaceable nose cone. The two U-ring seals can be seen on Delrin ${ }^{\mathrm{TM}}$ section of the sabot. 

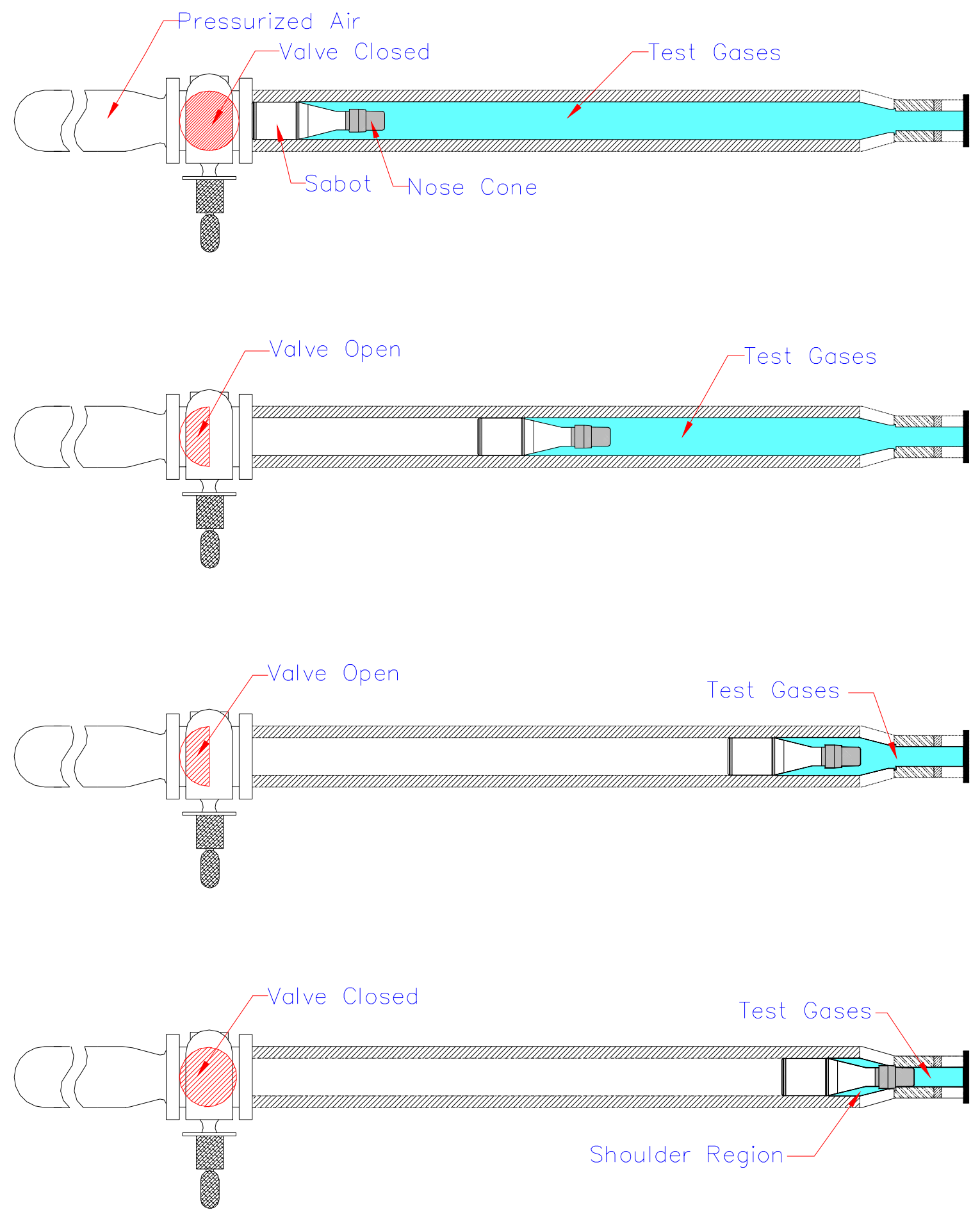

Fig. 5 Depiction of the UM-RCF in operation. a) Driven section is charged with the test gas mixture prior to start of test. Driver section is charged with high-pressure air. b) Hydraulic valve is opened and highpressure gas from the driver section propels the sabot down the length of the driven section. c) Sabot travels down the length of the driven section, compressing the test gas mixture ahead of the sabot. d) 
Sabot is lodged in the extension section, trapping the test gas mixture within the test manifold. The annular region of the test gas mixture, which includes most of the fluid disturbances caused by the travel of the sabot down the length of the driven section, is trapped in the shoulder region. 


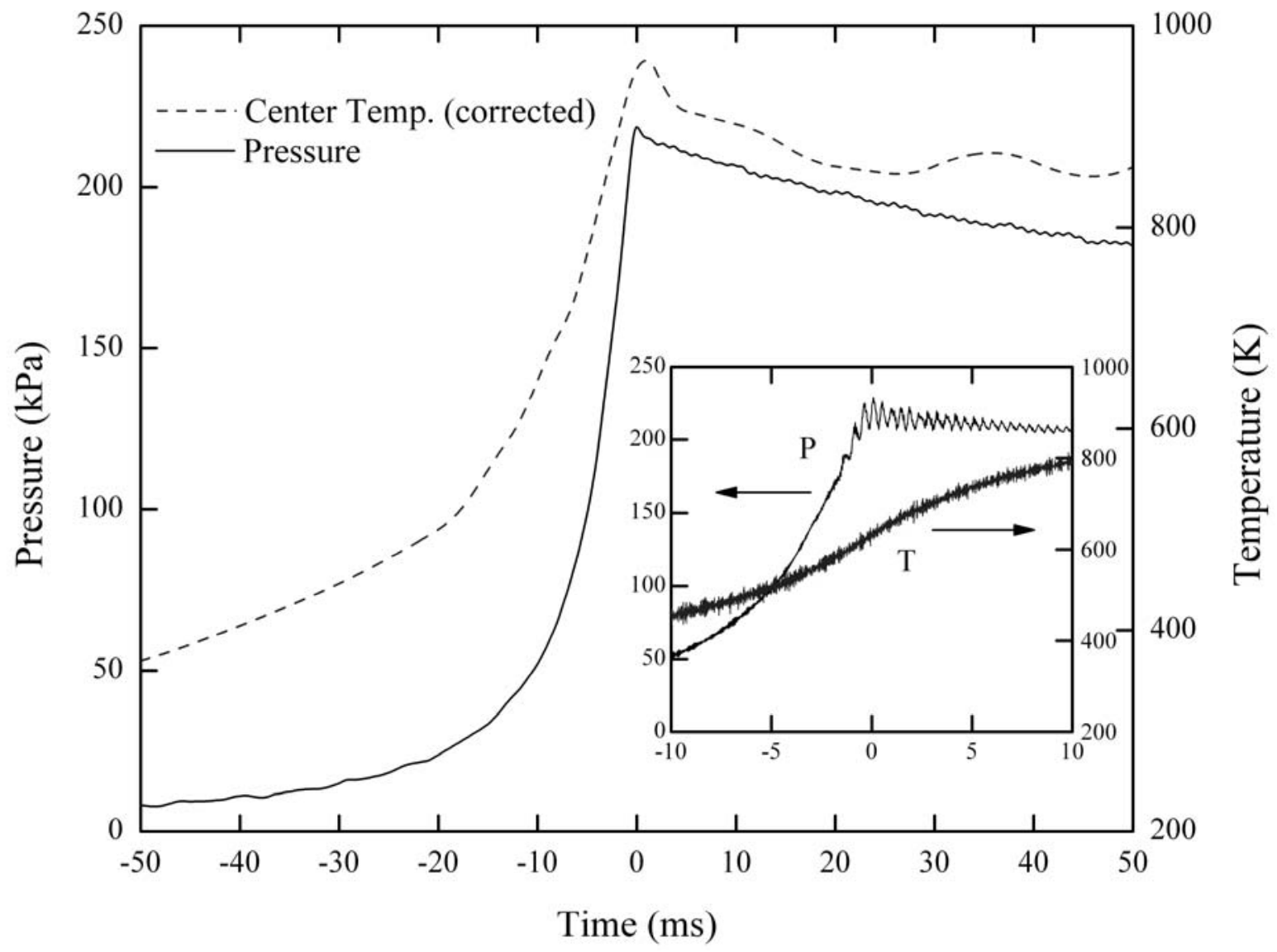

Fig. 6 Typical pressure and temperature time-histories from an UM-RCF experiment using an $\mathrm{N}_{2} / \mathrm{O}_{2}$ mixture as the test gas $\left(95.9 \% \mathrm{~N}_{2}\right.$, balance $\left.\mathrm{O}_{2}\right), P_{\mathrm{o}}=3.37 \mathrm{kPa}$. The inset shows raw pressure and temperature traces. 


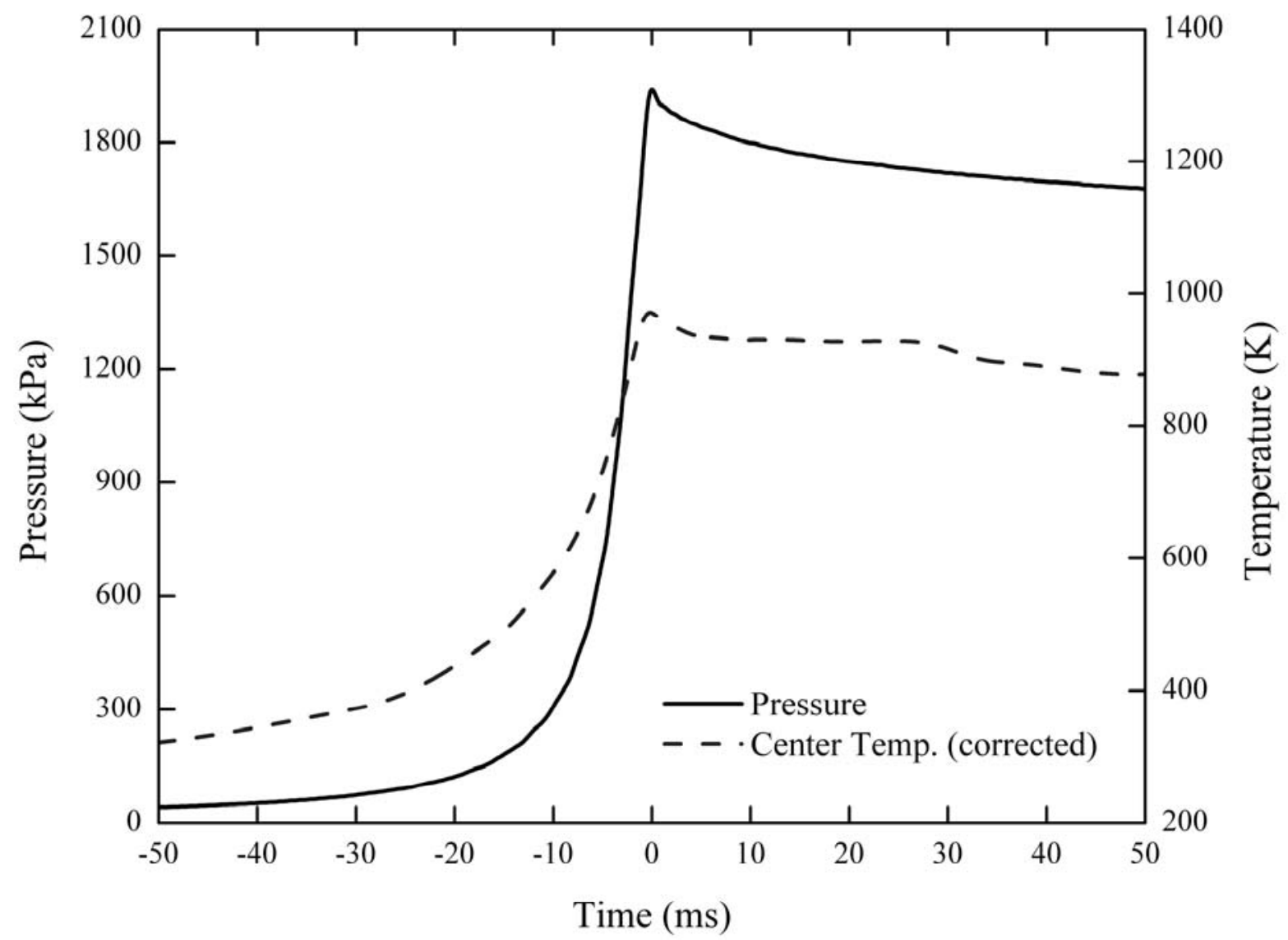

Fig. 7 Typical pressure and temperature time-histories from an UM-RCF experiment using $\mathrm{N}_{2}$ as the test gas, $P_{\mathrm{o}}=26.7 \mathrm{kPa}$. 


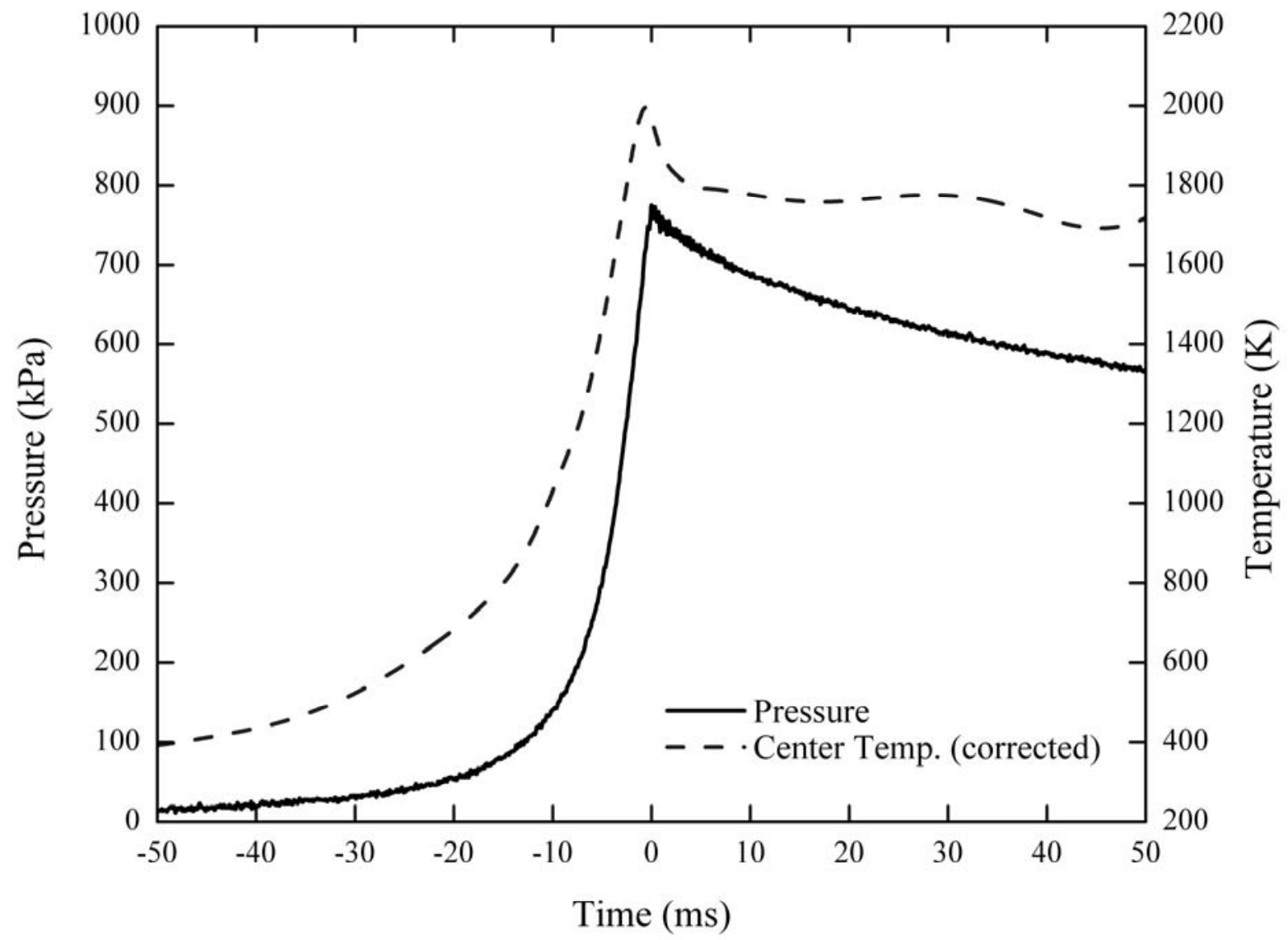

Fig. 8 Typical pressure and temperature time-histories from an UM-RCF experiment using Ar as the test gas, $P_{\mathrm{o}}=6.01 \mathrm{kPa}$. 


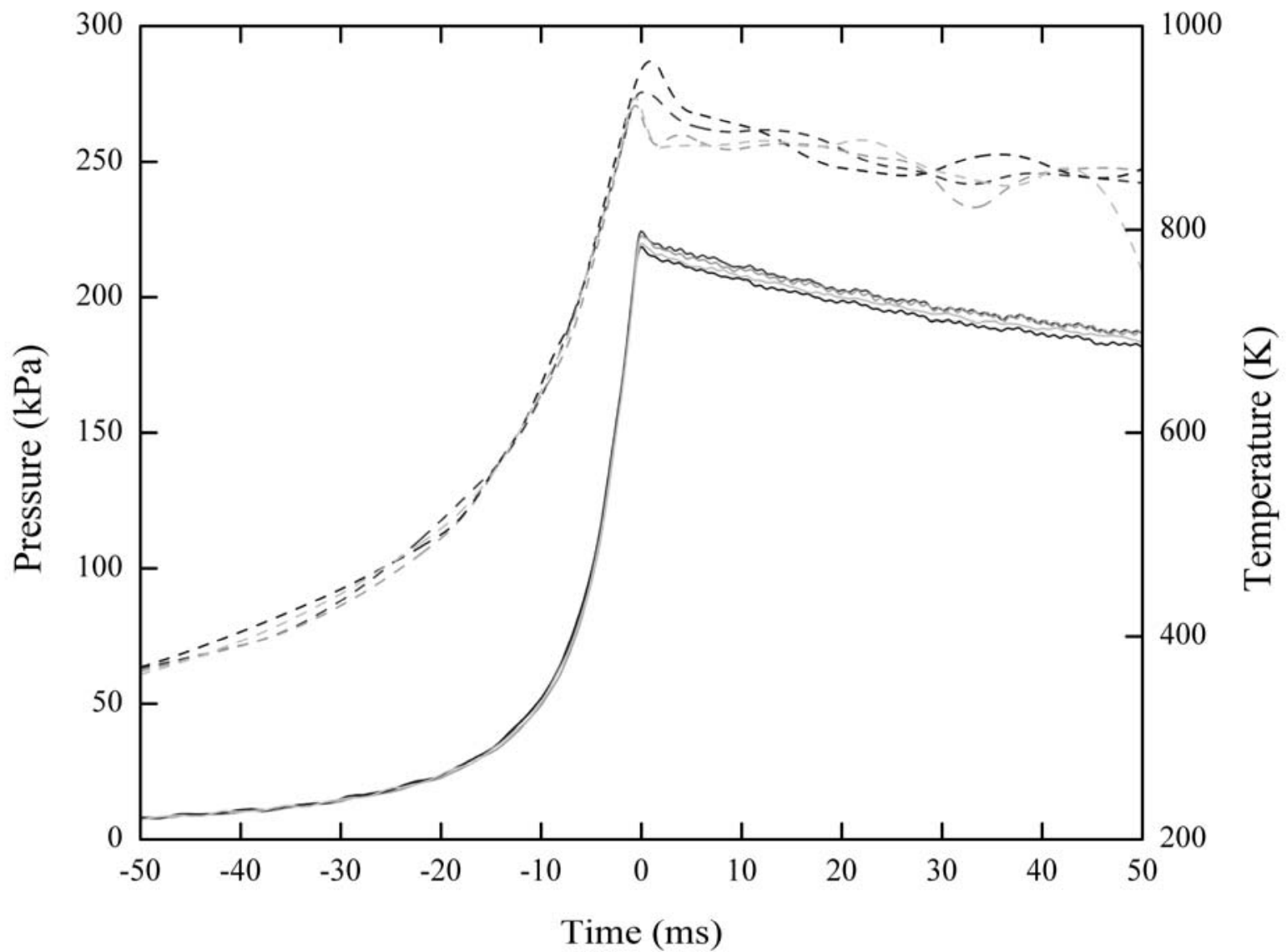

Fig. 9 Four UM-RCF experiments using an $\mathrm{N}_{2} / \mathrm{O}_{2}$ mixture as the test gas, which demonstrate experimental repeatability. Mixtures were $95.9 \% \mathrm{~N}_{2}$ and each experiment had a nominal initial pressure of $3.4 \mathrm{kPa}$. Dashed lines are center thermocouple data (corrected). Solid lines are pressure transducer data. 


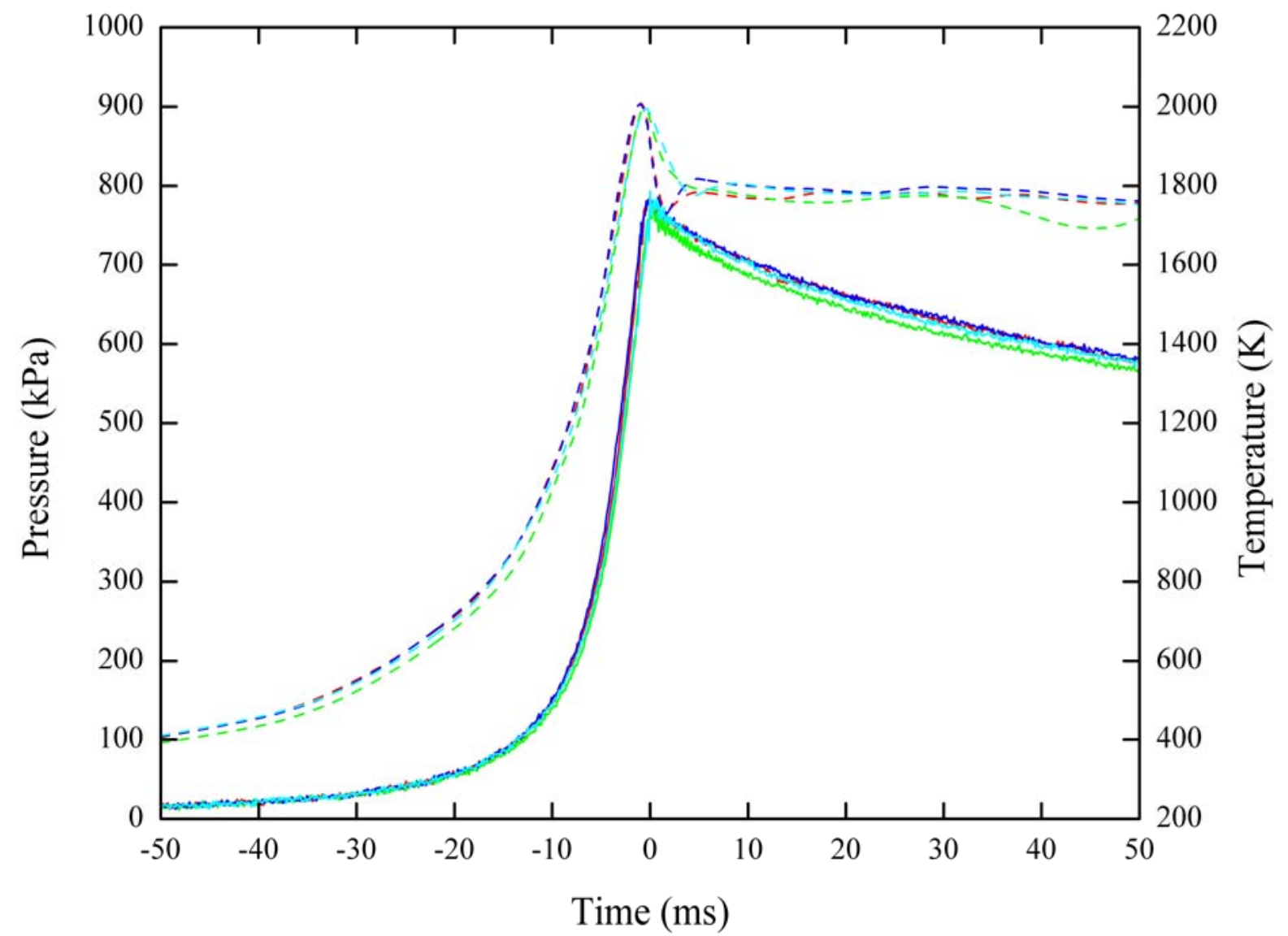

Fig. 10 Four UM-RCF experiments using $\mathrm{Ar}$ as the test gas, which demonstrate experimental repeatability. Each experiment had a nominal initial pressure of $6.0 \mathrm{kPa}$. Dashed lines are center thermocouple data (corrected). Solid lines are pressure transducer data. 


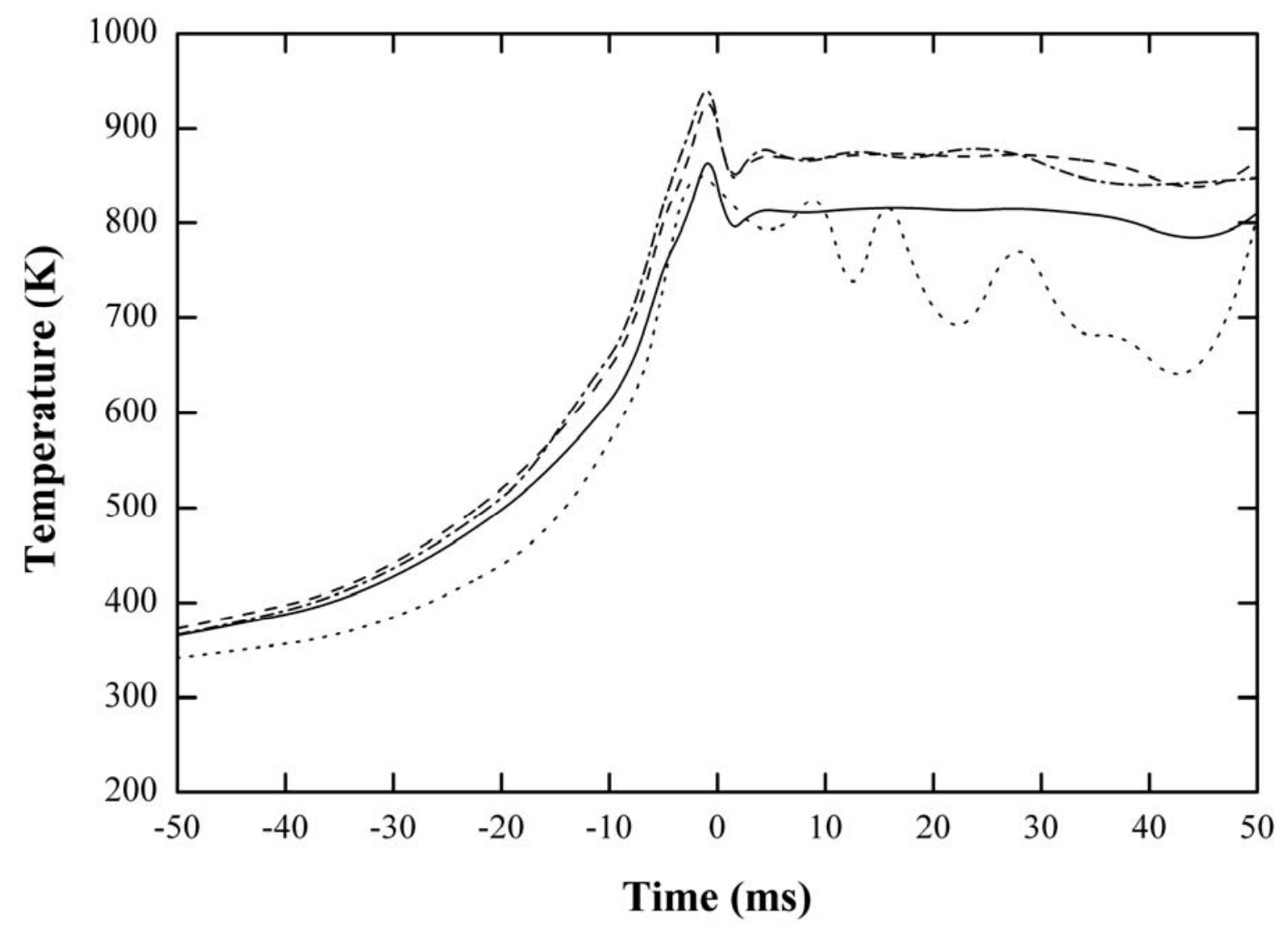

Fig. 11 Corrected temperature profiles measured at three radial locations for an UM-RCF experiment with $\mathrm{N}_{2}$ as the test gas, $P_{\mathrm{o}}=3380 \mathrm{~Pa}$. The thermocouples were located $25.4 \mathrm{~mm}$ (center, dashed line), $10.4 \mathrm{~mm}$ (dash-dotted line), and $2.9 \mathrm{~mm}$ (dotted line) from the wall of the thermocouple manifold. The $T_{90}$ temperature, Eqn (7), is indicated by the solid line. 


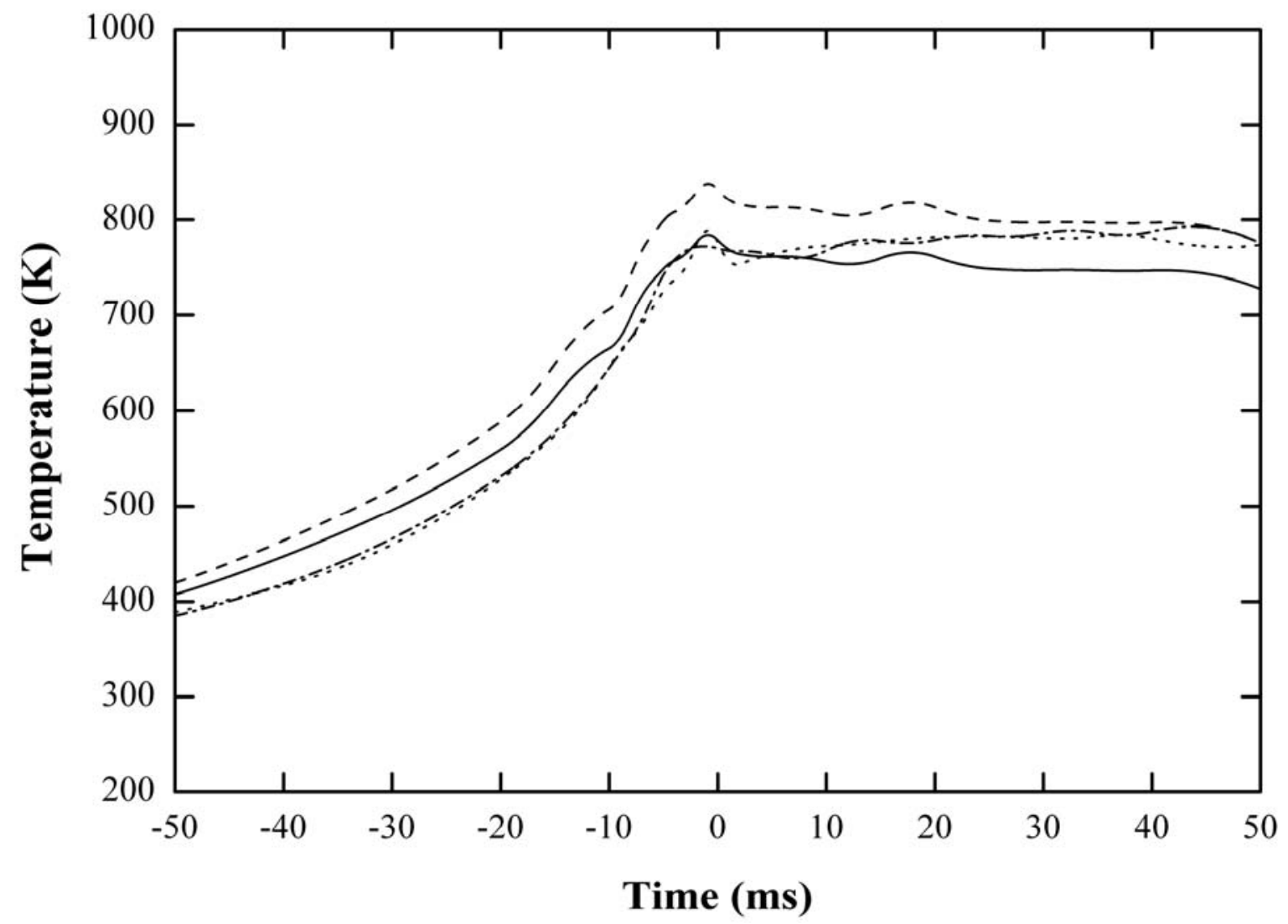

Fig. 12 Corrected temperature profiles measured at three radial locations for an UM-RCF experiment with $\mathrm{N}_{2}$ as the test gas, $P_{\mathrm{o}}=4560 \mathrm{~Pa}$. The thermocouples were located $25.4 \mathrm{~mm}$ (dashed line), $7 \mathrm{~mm}$ (dash-dotted line), and $5 \mathrm{~mm}$ (dotted line) from the wall of the thermocouple manifold. The $T_{90}$ temperature, Eqn (7), is indicated by the solid line. 


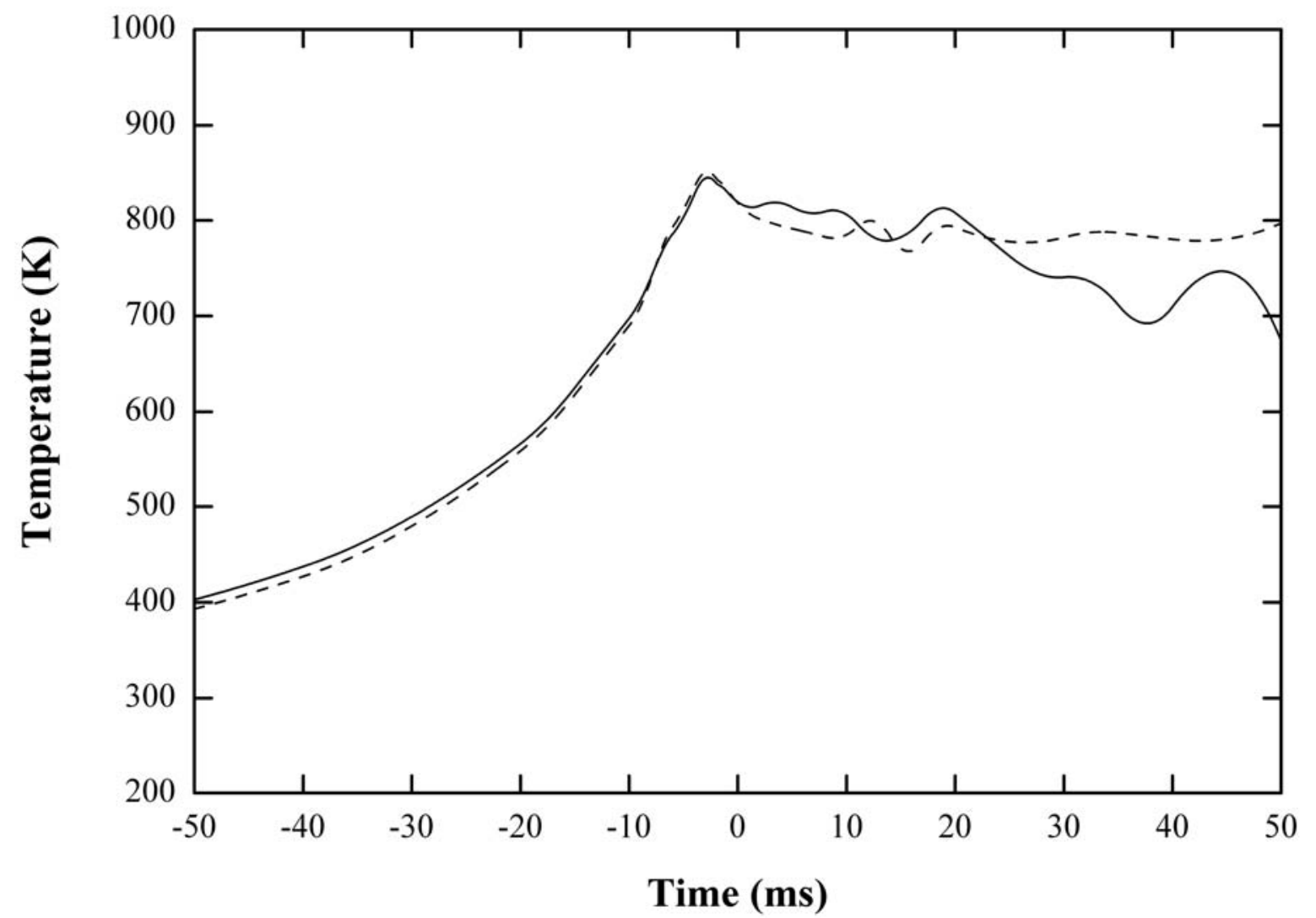

Fig. 13 Corrected temperature profiles at two axial locations for an UM-RCF experiment with $\mathrm{N}_{2}$ as the test gas, $P_{\mathrm{o}}=4560 \mathrm{~Pa}$. The thermocouples were located at the radial center of the test manifold and at $64 \mathrm{~mm}$ (dashed line) and 170 (solid line) $\mathrm{mm}$ from the end wall. 


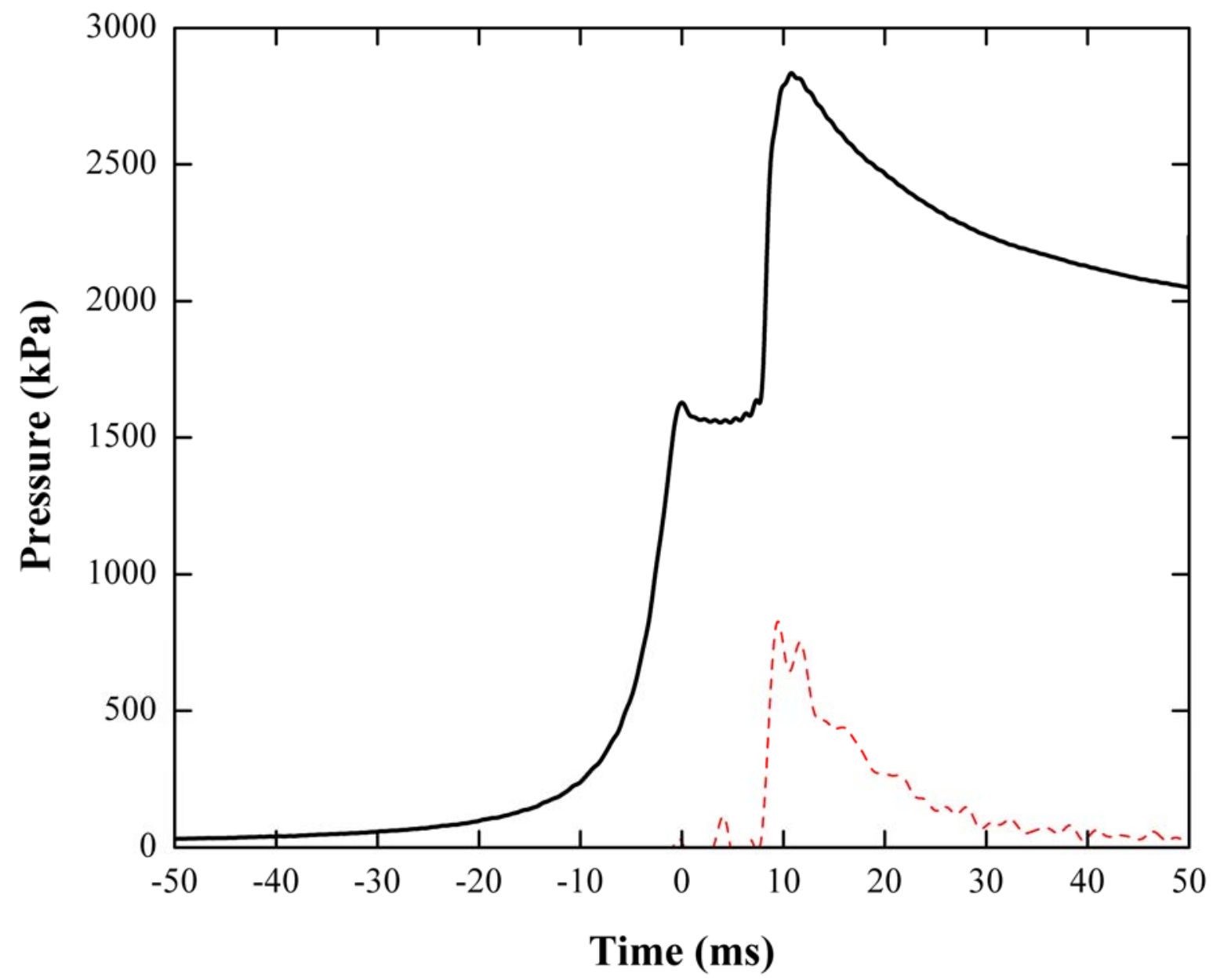

Fig. 14 Typical pressure (solid line) and light-emission (dashed line) time-histories from an UM-RCF experiment using $\mathrm{C}_{8} \mathrm{H}_{18} / \mathrm{O}_{2} / \mathrm{Ar} / \mathrm{N}_{2}$ (mole fractions of $0.0053,0.1659,0.1001$, respectively, balance $\mathrm{N}_{2}$ ) as the test gas, $P_{\mathrm{o}}=18.1 \mathrm{kPa}$. 


\section{References}

1. H. Kellerer, A. Müller, H.-J. Bauer, and S. Wittig, Combust. Sci. Tech. 113-114 (1996) 6780.

2. C. K. Westbrook, W. J. Pitz, J. E. Boercker, H. J. Curran, J. F. Griffiths, C. Mohamed, and M. Ribaucour, Proc. Combust. Inst. 29 (2002) 1331-1318.

3. K. Epping, S. Aceves, and J. Dec, Society of Automotive Engineers SAE-2002-01-1923 (2002).

4. S.-M. Suh, M. R. Zachariah, and S. L. Girshick, J. Vac. Sci. Technol. A 19(3) (2001) 940951.

5. A. G. Gaydon and I. R. Hurle, The Shock Tube in High-Temperature Chemical Physics. Reinhold Publishing, New York, NY, 1963.

6. P. Beeley, J. F. Griffiths, and P. Gray, Combust. Flame 39 (1980) 255-268.

7. J. F. Griffiths, P. A. Halford-Maw, and D. J. Rose, Combust. Flame 95 (1993) 291-306.

8. A. Cox, J. F. Griffiths, C. Mohamed, H. J. Curran, W. J. Pitz, and C. K. Westbrook, Proc. Comb. Inst. 26 (1996) 2685-2692.

9. J. Clarkson, J. F. Griffiths, J. P. MacNamara, and B. J. Whitaker, Combust. Flame 125 (2001) 1162-1175.

10. J. F. Griffiths, Q. Jiao, M. Schreiber, J. Meyer, and K. F. Knoche, Proc. Comb. Inst. 24 (1992) 1809-1815.

11. C. K. Westbrook, H. J. Curran, W. J. Pitz, J. F. Griffiths, C. Mohamed, and S. K. Wo, Proc. Comb. Inst. 27 (1998) 371-378.

12. J. F. Griffiths and B. J. Whitaker, Combust. Flame 131 (2002) 386-399.

13. M. Ribaucour, R. Minetti, and L . R. Sochet, Proc. Comb. Inst. 27 (1998) 345-351. 
14. R. Minetti, M. Carlier, M. Ribaucour, E. Therssen, and L. R. Sochet, Combust. Flame 102 (1995) 298-309.

15. R. Minetti, M. Carlier, M. Ribaucour, E. Therssen, and L. R. Sochet, Proc. Comb. Inst. 26 (1996) 747-753.

16. R. Minetti, M. Ribaucour, M. Carlier, and L. R. Sochet, Combust. Sci. Tech. 113-114 (1996) 179-192.

17. P. Desgroux, L. Gasnot, and L. R. Sochet, Appl. Phys. B 61 (1995) 69-72.

18. P. Desgroux, R. Minetti, and L. R. Sochet, Combust. Sci. Technol. 113-114 (1996) 193-203.

19. M. Ribaucour, R. Minetti, L. R. Sochet, H. J. Curran, W. J. Pitz, and C. K. Westbrook, Proc. Comb. Inst. 28 (2000) 1671-1678.

20. P. Park, and J. C. Keck, Society of Automotive Engineers SAE-900027 (1990).

21. D. Lee and S. Hochgreb, Int. J. Chem. Kinet. 30 (1998) 385-406.

22. D. Lee and S. Hochgreb, Combust. Flame 114 (1998) 531-545.

23. S. Tanaka, F. Ayala, J. C. Keck, and J. B. Heywood, Combust. Flame 132 (2003) 219-239.

24. S. Tanaka, F. Ayala, and J. C. Keck, Combust. Flame 133 (2003) 467-481.

25. L. Brett, J. MacNamara, P. Musch, and J. M. Simmie, Combust. Flame 124 (2001) 326-329.

26. S. M. Gallagher, H. J. Curran, J. Würmel, J., and J. M. Simmie, “The Oxidation of Propane at Elevated Pressures in a Rapid-Compression Machine. An Experimental and Modeling Study," Proceedings of the Third Joint Meeting of the U.S. Sections of The Combustion Institute, Chicago, IL, USA, March 2003.

27. W. S. Affleck and A. Thomas, Proc. Inst. Mech. Eng. 183 (1969) 365-385.

28. G. F. Carrier, F. E. Fendell, C. T. Hsu, I. L. Stonich, and L. D. Bergerson, Basic Research on Flame Radiation, Report 91/0091, Gas Research Institute, 1991. 
29. J. F. Griffiths, Q. Jiao, W. Kordylewski, M. Schreiber, J. Meyer, and K. F. Knoche, Combust. Flame 93 (1993) 303-315. 